\title{
GXMNAS REATMIE]
}

1

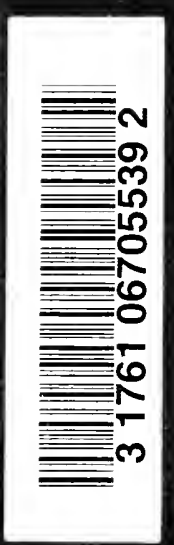
WOLNT AND MUSCLE DISABILITESS HE. DEANE 3. 35. 
$\mathrm{J}_{4}$ D

UNIVERSITY OF TORONTO DEPARTMENT OF PSYCHOLOGY 


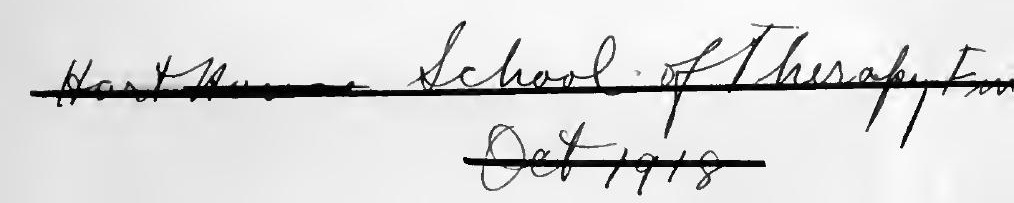


Digitized by the Internet Archive in 2007 with funding from Microsoft Corporation 


\section{GYMNASTIC TREATMENT}

FOR

\section{JOINT AND MUSCLE DISABILITIES}


PUBLISHED BY THE JOINT COMMITTEE OF HENRY FROWDE AND HODDER \& STOUGHTON AT THE OXFORD PRESS WAREHOUSE FALCON SQUARE, LONDON, E.C.L 


\title{
G Y M N A S T I C T R E A T MEN T FOR
}

\section{JOINT AND MUSCLE DISABILITIES}

\author{
Brevet Col. H. E. DEANE, R.A.M.C. \\ In Charge War Hospital, Croydon
}

WITH PIEFACE BY

Temp. Colonel A. CARLESS

army Medicat, Serrice

Consulti..g Surgeon, Eastern Command

AND BY

Brev.t Lieut.-Col. F. W. MOTT, F.R.S., R.A.M.C. (T.) Mauds:ey IIospital, Denmark Ilill

LONDON

HENRY FROWDE OXFord UNIVERSITY Press
HODDER \& STOUGHTON ,WARWICK SQUARE, E.C. 
PRINTED IN GREAT BRITAIN

BY HAZELL, WATSON AND VINEY, LD , LONDON AND AYLESBURT.

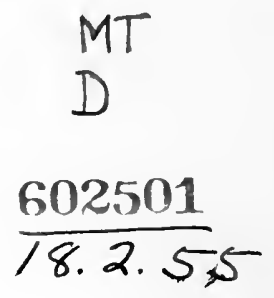




\section{DEDICATED TO}

\section{SIR ALFRED KEOGH, G.C.B.,}

DIRECTOR-GENERAL, ARMY MEDICAL SERVICF. 



\section{PREFACE BY COLONEL A. CARLESS}

DURING the past three and a half years it has been my privilege to be engaged almost without a break in attending to sick and wounded soldiers in various spheres of duty. At first my work was at a well-equipped Territorial hospital, as well as in a private hospital for officers in a large London nursing home. For the last fifteen months, however, I have been acting as Consulting Surgeon in the Eastern Command, a command which provides by far the largest number of beds of any in the country, and in this position my outlook on the methods and results of treating our wounded men has been broadened and widened to a marked extent. I have seen them arriving in the hospital ships from France, and being skilfully and quickly transferred to hospital trains, whereby they were comfortably transported to all parts of the 
country. I have watched their treatment in large military hospitals, Territorial hospitals, civilian hospitals, voluntary aid hospitals both primary and secondary, and in various convalescent institutions. I have followed them further into convalescent camp and command depôt, and also into orthopædic centres, and there is but little in the great healing and reparative machinery evolved by the Army Medical Service under the efficient and far-seeing leadership of Sir Alfred Keogh that I have not been privileged to sample and investigate.

Naturally there has been much to learn, much to admire, and much to praise, both from the standpoint of organisation, surgical skill, and personal devotion to duty. But one has also to admit that one has seen failure and mistake in not a few directions. Hidebound submission to antiquated methods, and a blind trust in exploded theories, have spoilt the chances of recovery in many a case ; insistence on obedience to rules and methods organised for work in peace time has put the brake on the wheel of progress in many directions; and the employment of valuable 
PREFACE BY COLONEL A. CARLESS 13

agencies in unsuitable conditions by individuals who are ignorant alike of methods and results but are helplessly carried in the train of popular imagination, has been responsible for much that is defective.

Attention has been, and is being, drawn to these failures in various ways, and methods of preventing or alleviating them are being devised. It was apparent in comparatively early stages of the war that a great aftermath of painful disability and crippling deformity was going to be left which would require all the available skill and energy of the medical profession to combat effectively. Sir Robert Jones has taken up this challenge fearlessly, and by precept and practice is leading the attack; orthopædic centres with their operative, technical, and re-educational departments are doing invaluable reparative work. Instructions in "preventive orthopædy" are being administered in small and large doses by consulting surgeons throughout the country, and the development of conditions requiring orthopædic treatment is being thereby prevented; but still there is abundant room for the evolution of more effective 
methods of treating physical disabilities than those already employed.

Hitherto chief reliance has been placed on massage to set free stiff joints and limbs -a most valuable and helpful agent when rightly applied. Devoted women have given themselves up to the carrying on of this work, and most admirable results have often been obtained; but with every desire to appreciate their work and with no desire to belittle its value, one has had forced on one's mind sundry factors that indicate limitations in its utility.

(1) The ordinary medical man who orders massage for a patient knows nothing from personal experience of the methods employed, or of the results obtained or obtainable. He hands the patient over to the " massage department" with smug satisfaction that he has done his duty in an up-to-date fashion, and troubles no more about the matter.

(2) The massage is carried out as a rule by a woman who knows nothing but massage and perhaps a little electricity, and her horizon being thus limited, she will continue massaging a case most assiduously and devotedly when all hopes of gaining 
PREFACE BY COLONEL A. CARLESS 15

improvement thereby have long ceased. Often has one seen hopelessly ankylosed joints being rubbed to regain movement, and limbs with divided and unsutured nerves being similarly treated. The limitations of a woman's strength must also be remembered, and it is pathetic to see a little but devoted masseuse struggling with a strong man's stiff shoulder held by powerful muscles; to get the patient's weight to act upon the arm would do more towards regaining movement in five minutes than five months of massage.

(3) A third point that has been abundantly brought home to me has been that to get good results the patient's own will must be brought into action. There are no particular inducements for the fighting man to get well more quickly than he can help; the allurements and comforts of the trenches are not such as to urge him to rapid convalescence, and he is quite ready to go on being rubbed or having passive movements of limbs at the hands of a masseuse, or in the grasp of a machine, as long as may be without himself putting out an ounce of effort to hasten the cure. 


\section{PREFACE BY COLONEL A. CARLESS}

What is true of the massage department is also true even to a greater degree of the many and expensive machines that have been introduced in order to restore mobility to stiff limbs. I have had the opportunity of seeing the wonderful machinery employed for this purpose at the Grand Palais in Paris, and whilst one appreciates the skill and ingenuity here manifest, the same feelings are again produced, viz. that the work is being done for and not by the man. Passive mobility is produced pretty easily, whereas what is required in order to fit men once again for work in front-line trenches is active work. Moreover one cannot but be impressed with the expense involved in the setting up and maintenance of a large massage department or with the acquirement and working of elaborate mechanical appliances, to which also are frequently superadded hydrotherapeutic and thermic appliances, such as radiant heat baths, whirlpool baths, etc., delightful and useful as they are, but expensive to a degree.

At the Croydon War Hospital, Colonel Deane has proved to us that it is possible 
PREFACE BY COLONEL A. CARLESS 17

to do without a great amount of this extravagant paraphernalia, trusting merely to simple gymnastic methods and inexpensive apparatus, such as the vertical rope, parallel bars, the sparred plank, etc. Colonel Deane has studied his subject practically, and knows the effect of every movement and each exercise from personal experience; he has himself done everything he recommends from alpha to omega, and he has keen and enthusiastic helpers, small and decidedly select in numbers, who are ready and willing to carry out his wishes and orders. I have had the opportunity of seeing the work in the gymnasium on many occasions, and I have personally seen men before and after treatment; one or two of the cases mentioned in the following pages were sent to Croydon by me for this treatment, and $I$ have been more than satisfied with the results. To gain such results, however, it is essential that the instructor and doctor should himself have gone through the whole course of exercises employed. Unfortunately at present there are few doctors who know or care anything about these matters. Is it too much to 


\section{PREFACE BY COLONEL A. CARLESS}

hope that when at length the cessation of this war restores medical education to normal conditions, all medical students will be necessarily obliged to undergo military training, during which a course of physical gymnastic exercise will be included, and there will come the opportunity of explaining to them the value of movements and exercises such as those described in this book in the restoration to use of limbs crippled by accident or disease?

For the doctor must be made to recognise the fact that a fracture is not cured merely when the bone has once again been restored to continuity, or a dislocation put to rights when it has been reduced and the painful swelling has disappeared. It is just as important for the doctor to secure full restoration of function of the limbs as to effect the complete union of the divided ends of the bone. In military work, too, the medical man must ever keep in mind the necessity of fitting a man to return to the fighting line as quickly as possible. Physical disabilities following gunshot wounds are mainly due to the presence of cicatrices in skin, sub- 


\section{PREFACE BY COLONEL A. CARLESS 19}

cutaneous tissues, or muscles; sometimes to adhesions in joints, and these may be slight or comparatively slender, or massive; and not infrequently to displacement of portions of bones which may have united in faulty positions. It is obvious that a careful examination by radiography and palpation must be made before any definite course of treatment is recommended. Gross bony deformity frequently requires operative treatment. In the absence of osseous deformity, it is necessary to decide whether the limitation of movement is due to intra- or extraarticular causes, or to both. The history of the case and perhaps the radiograph will help to decide whether there is much trouble in the joint. If it is probable that no great trouble is present, it is then quite possible that limitations in movement may be due to some slight adhesion which may be broken through by forcible movement under an anæsthetic ; but one must here warn readers to be very careful how they attempt such a procedure in the presence of chronic septic lesions in the body; and especially is this warning needed in the case of stiff knees 
complicating the later stages of compound fractures of the femur with septic sequestra and sinuses still present. Only recently I saw two cases in one hospital where attempts to mobilise the knee joints had in each case been followed by suppuration in the joint, the pus being mixed with blood clots due to forcible rupture of the adhesions. When there is any likelihood that massive adhesions are present, the attempts to mobilise the joint under an anæsthetic must be directed rather to stretching the adhesions gradually than to rupturing them suddenly. The cases which are most likely to derive benefit from gymnastic treatment such as undertaken at Croydon under Colonel Deane are those in which limitation of movement is mainly due to presence of rigid and dense scars in the muscular substance. Many such cases exist as the result of gunshot wounds, and one is quite satisfied that active treatment such as that recommended here will be followed by satisfactory results more quickly and at infinitely less expense than by other methods. Massage, machinery, hot baths, electrical stimulation of muscles, etc., all 


\section{PREFACE BY COLONEL A. CARLESS 21}

have their place, and are valuable in that place ; but for rapid restoration of function and for the building-up of the patient's will to work nothing can surpass in rapidity or cheapness the gymnasium under the supervision of such an officer as Colonel Deane.

\section{A. CARLESS.}

February 1918. 

PREFACE BY BT. LT.-COL. F. W. MOTT

I HAVE long been interested in Colonel Deane's gymnastic treatment of soldiers' disabilities owing to paralysis and contractures of limbs, whether of functional origin or due to surgical injuries, and I welcome therefore an account of the methods which he has so successfully carried on at the Croydon Military Hospital.

This little book, describing the various exercises, should stimulate medical men to adopt this mode of treatment more often, rather than the routine of massage, electricity, and machines applied indiscriminately to every case of paralysis or contracture. Colonel Deane very properly points out that it is necessary to select the cases which are suitable for gymnastic treatment. He also emphasises the desirability of the medical man himself knowing how to perform the various exercises, and the special use of each in restoring 
function and removing the disability, for he can only really appreciate the value of each exercise by knowing the feeling produced by its execution.

The success of any treatment of paralysis or contracture largely depends upon the enthusiasm the medical officer shows. Colonel Deane's enthusiasm is unbounded, and infects those who are carrying out his principles, both instructors and instructed. The minds of all are put into the work, and that is the essential difference between a well-conducted gymnasium and an institute with machines for automatically moving the limbs. The mind can be occupied with something else while the limb is being moved by the machine, whereas in gymnastics there is a successive flow to the brain of kinoesthetic impulses varying in their nature and intensity as each successive movement is carried out. There is also a corresponding outgoing flow of voluntary motor impulses. The arrival and departure platform of these ingoing and outgoing nervous impulses is the cerebral cortex presiding over volition, which in the case of gymnastic exercises has to control and check their 
PREFACE BY BT. LT.-COL. F. W. MOTT 25

arrival and departure, and make the necessary adaptations for changing conditions.

Gymnastics, such as the parallel bars, the vertical rope, the horizontal bar, and the sparred plank, simple in themselves, are most excellent for the practice of associated movements. These are valuable because they are represented in each half of the brain; therefore supposing a paralysis of one limb exists, there is always a tendency for it to be raised by muscles which habitually are used in bilateral association.

Functional paralysis and contractures of all kinds are psychogenic and due to an "idea" generally arising in a psychogenic individual. The idea of the disability tends to become fixed and firmly installed in the mind by daily massage and electricity, especially when carried out by sympathetic women. These cases can be cured by faradism and persuasion in two or three sittings. The cases should afterwards be treated by appropriate exercises.

A large number of paralysis and contractures, due to an original gunshot or 
26 PREFACE BY BT. LT.-COL. F. W. MOTT

other injury, have a large halo of functional disability, and it is in such and purely hysterical cases that we may apply Charcot's maxim, "C'est la foi qui sauve, ou qui guérit." Now, nothing excites faith so much as seeing what treatment has done for others, and this is one of the great advantages of gymnasium classes for disabled soldiers. Moreover, another advantage is emulation, which acts as a powerful stimulus to the will in re-education, and a great many men thus treated are so far restored physically as to be fit for military service or able to return to their occupation.

FRED W. MOTT.

February 16th, 1918. 


\section{CONTENTS}

Preface by Temp. Colonel A. Carless

Preface by Brevet Lieut.-Col. F. W.

MotT, F.R.S. • • • $\quad$ • $\quad$ • $\quad$ - 23

Advantages of Applied Gymnastics . 31

On Movements Generally • . . 45

The Hand Bag . $\quad$. $\quad$. $\quad$. 52

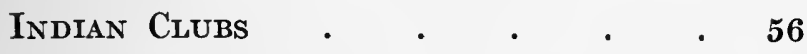

The Skipping-Rope . . . . . . 71

Wrist Rollers and Pulley Machines 72

The Vertical Rope . . . . $\quad 75$

The Parallel Bars . $\quad$. $\quad$. $\quad$. 91

The Sparred Plank . . . . 108

The Beam . . . . . . 115

Leg Exercises . $\quad$. $\quad$. 119

The Wall Bars . . . . . 131

The Nautical Wheel . . . . 134

Games • • • • • . $\quad$ • 137 



\section{LIST OF ILLUSTRATIONS}

PIG.

1. Hand Bag .

2. Indian Cluub

3. Position 1 . Position 2 . Position 3 . Position 4 .

4. Position 2 . Position 3 . Position 4 .

5. Condition on Admission . $\quad$ • 66

6. Patient supinating Left Hand One

Month after Treatment • • 68

7. Patient performing Short Circles behind Shoulder Six Weeks after Treatment • $\quad$ • $\quad$ • $\quad$. 69

8. Rope Climbing, Position 3. . . 79

9. Rope Climbing . $\quad$ - $\quad$. $\quad$ • $\quad$. 82

10. Rope Climbing, Position 2. • . 83

11. Extent of Free Movement after Two Weeks' Preliminary Treatment on Nautical Wheel • • $\quad 85$

12. Back Bend by Man with Paralysis of Left Arm, after One Month's Treatment 
IFIG.

13. Showing Position of Rest between the Bars: Long Arm and Short ARM . . . . . . 93

14. Severe Wound of Left Shoulder, with Complete Immobility of Arm before Treatment . . . . 101

15. Position attained by Patient after 'Three Months' Treatment . 103

16. Showing Scars of Men on Parallel Bars in Fig. 13 . 13 . 107

17. Use of Sparred Plank in Arm DisABILITIES . $\quad . \quad$. $\quad$. 110

18. Use of Sparred Plank in Leg DisABILITIES . $\quad$ • $\quad$ • $\quad$. $\quad$. 111

19. Method of treating Disabilities of Trunk AND Lower Limbs • • 116 20. Method of treating Disabilities of Trunk AND UPper Limbs • . 117

21. Exercise for Thigh Muscles and KneE JoINTS . . . . . . 124

22. Second Position . . . . 125

23. Method of applying Wall Bars to Upper and Lower Limb Disabilities 133 24. Use of Nautical Wheel for DisabiliTIES OF UPPER LIMBS . . . 135

25. Game of "Twos and Threes" • . 138 26. Game of "Twos and Threes" . . 139 


\section{GYMNASTIC TREATMENT}

FOR

\section{JOINT AND MUSCLE DISABILITIES}

\section{ADVANTAGES OF APPLIED GYMNASTICS}

ThIs book has been written to invite attention to a point connected with the treatment of certain physical disabilities which result from wounds and other injuries. Among the many different forms of special treatment which have been introduced into our various hospitals, the application that can be made of ordinary simple gymnastic exercises on simple apparatus has been more or less completely overlooked.

The use of the word "gymnastics" to those who are not personally familiar with the application that can be made of them 
may conjure up visions of men doing "grand circles" on the horizontal bar, or "long-arm changes" on the parallel bars, and may suggest the thought: "What is the good of talking about gymnastics in connection with disabled men ?" No doubt the thought is natural, but it illustrates the danger attached to thinking without trying. As Hunter said to Jenner when the latter expressed his thoughts on the possible effects of vaccination : "Why think? Why not make the experiment?"

In connection with my subject, the word simply means that gymnastic exercises are reduced to their elements and made applicable to any man who may be capable only of the barest movement. The term "gymnastics" conveys more to the average man's mentality than the word " exercises," which is no light advantage. Both at the medical schools and in medical text-books, the subject of gymnastics and their practical application to the treatment of physical dis. 
abilities is wholly ignored. Consequently, lack of knowledge results in patients being put under the care of either the advocates of some particular and exclusive so-called system, or of the manipulators of some machine for which phenomenal virtues are claimed-often to the sole advantage of the manufacturer.

I wish to make it clear that I am not dealing with cases of organic nerve lesions or paralysis resulting from severed nerves. The effective treatment of a disability by voluntary movements naturally presupposes an intact connection between the motor centres and the periphery. A definite diagnosis is made before putting a man on gymnastic treatment. At the same time it may be remarked that many cases of organic lesions of the nervous system have a functional element superimposed, as Lieutenant-Colonel Mott points out in his Preface, and such elements can be treated by simple gymnastic means very effectively.

'Two years' war experience at this 


\section{GYMNASTIC TREATMENT FOR}

hospital has clearly demonstrated that massage, radiant heat, and electricity have been applied in many instances month after month with little or no benefit, till the patient had arrived at a stage when it was hardly possible to rouse him from the physical and mental inertia into which he had been allowed to drift.

The problem has to be attacked from the point of view of the man himself, of the man's "will-to-do," and it has become increasingly clear that this object has been largely lost sight of because attention has been so exclusively focussed on academic methods of treatment. Any method of treatment which lacks the essential factor of stimulating and encouraging the man's own power of "will-todo," which has been inevitably weakened by the stress through which he has passed, stands self-condemned.

From experience gained here, I can confidently state that, had simple voluntary movements been commenced months earlier, a very large number of cases 


\section{JOINT AND MUSCLE DISABILITIES 35}

need never have been sent here or to any other special hospital.

One has only to watch massage as ordinarily practised with movements of joints to see that the man is practising no volition at all, and making no effort to use his own muscles. Nor can he be blamed, for there is no stimulus or inducement held out to him to do so, while any twinge of pain he may get acts as a further discouragement. I have known men sent to the gymnasium who have been treated for months by massage, etc., and on being set to work, say: "But that hurts!" It did not hurt a day or two later.

This factor of volition is vital. The man must do things himself, and exercise his own volition and put his own motor centres into action; in other words, the "will-to-do" must be stimulated and cultivated. A fraction of movement obtained in that way is infinitely more valuable than any greater amount of movement obtained by passive methods. 
This volition can be induced by exercises on apparatus and by the use of simple appliances such as a skippingrope, Indian clubs, etc., but their application can be directed only by knowledge of the use of these appliances and of the means to adapt them to the requirements of the individual. In addition to cultivating a man's volition, gymnastic exercises on apparatus enable full use to be made of associated movements.

It is of the utmost importance to understand the use that can be made of the man's sound limbs to enable him to recover the use of an injured one. Attention is too much centred on obtaining some anatomically correct movement; meantime all the other limbs are allowed to remain inactive, and if the anatomically correct movement cannot be obtained, then the case is given up as incurable. Such concentrated treatment ignores the value of associated movements of joints brought about by muscles passing over one or more joints. Take the case of a 
man who cannot flex one joint of the upper or lower limb, or who can only partially flex a joint. In addition to any special effort to flex that joint singly, it is important to get him to flex all the sound joints of the limb, which all tends to make him capable of flexing the injured one. Further, such are the intricacies of muscular association which defy anatomical differentiation, that in doing some exercises, if his lower limb joints are flexed, it will react on the joints of his upper limbs and they will tend to flex also.

It is easy to overlook the importance of training a limb to perform its function more or less regardless of anatomical perfection. It is easy to overlook the fact that, if one joint is defective, other associated joints will make good the deficiency. An illustration of an actual case may be of service. A man with both forearm bones broken has cross-union interfering with pronation and supination. Now the greatest and most powerful movements of pronation and supination 
take place by means of internal and external rotation of the shoulder joint; therefore, proceed to cultivate that substitute. Such men are urgently wanted, and need not be kept under treatment if they can fulfil the postulates laid down at the War Hospital, Croydon, to qualify a man for discharge in Category A, viz. :

I. To use and fire a rifle.

II. To throw a bomb.

III. To get in and out of a trench.

When I assumed charge of this hospital I applied for authority to equip a gymnasium for the purpose of treating disablements in soldiers. This was granted. I selected the apparatus from the equipment of the military gymnasia of former days with the addition of a Swedish beam instead of the ordinary gymnastic beam. At the same time I applied for the services of Lieutenant E. Stafford, Durham Light Infantry, who had been promoted from the Army Gymnastic Staff at the outbreak of the war, and whose 
qualities I knew from several years' experience of his work to be well adapted for the purpose I had in view, and the Army Council granted my application.

An advantage of apparatus work is that it admits of many varied ways of obtaining the same end, whereas the use of machines is stereotyped and monotonous, to which further reference will be made.

Work on apparatus enables a man to use not only his injured limb, but also his healthy ones, and where the injury is such that he cannot perform a certain movement himself, he can be assisted by the instructor. In cases where the injured limb cannot be dealt with in one way, a knowledge of the use of apparatus enables it to be dealt with in another. A good deal depends on the ingenuity and personal qualities of the instructor, whose services can be enormously enhanced by a medical man with sufficient knowledge to make a personal and practical application of gymnastics. 
To enable advantage to be taken of various exercises and to appreciate how to apply them it is necessary to have an idea of doing them oneself, for otherwise it is impossible to appreciate the effects of the exercises and the associated movements.

The medical man should be able to demonstrate himself what he wants done, and be able to judge of the efficacy of what he sees his assistant doing. Indeed, the medical man should be able to do more than he will ask a patient to do, as he will then be in a better position to pick an exercise to pieces, so to speak, and adapt it to the patient's capabilities.

The value of an object-lesson is no less in this sphere of work than in any other, perhaps greater. The medical man and the instructor should show the required movement or exercise with precision, and demonstrate to the patient how each of his difficulties can be overcome step by step. This has a moral and stimulating effect which is entirely 
JOINT AND MUSCLE DISABILITIES 41

lacking in saying to a man "do so-andso," and obviates any suggestion arising in the man's mind as to whether his adviser can do it himself.

Much valuable time is lost by not putting men on gymnastic treatment early enough. Boards have frequently been held here on officers who were having sick leave extended month after month, and very often nothing done for them, and who only wanted simple gymnastic exercises which their medical advisers were unable to prescribe for them. Some have voluntarily attended the gymnasium here, with results that they had not thought possible.

All the apparatus necessary to cultivate any movement which a soldier is likely to want, and on which work can be adjusted to suit any man fit for exercise at all, are a skipping-rope, Indian clubs, dumb-bells, a beam, a slanting ladder, a sparred plank, parallel bars, wall bars, ropes, and a nautical wheel. The expense is trifling. If space and expense are 
considerations, the wall bars can be omitted, for they can be replaced by the slanting ladder and sparred plank which allow of a very much greater range and variety of movements. If the requisite skilled supervision be obtainable and a building sufficiently large be available, other apparatus can be installed which provide excellent means of treating various disabilities, and at the same time an entertaining variety of movements ; fixed poles, vertical and slanting; swinging poles; the knotted rope; the climbing wall; and a horizontal bar, or an iron bar as was used in former days, both of which are better suited for regaining power of grip than the beam.

Then there are several movements practised by professional dancers and acrobats which have a valuable application to the treatment of disabled limbs and require no apparatus.

I do not mean to imply that good results are not obtained by other means than by the apparatus-work as advocated 
here, but it is maintained, and can be demonstrated, that in very many cases better results can be obtained more quickly and more certainly by these more simple means.

It is not expected that a man should attain perfection of position on apparatus. All that is aimed at is the recovery of the use of his limbs. Indeed a great deal of valuable time can be wasted by paying too much attention to the exactitude of a minor movement or position, which is of no real practical value. There is a tendency to lose sight of the fact that the predominant object of every medical officer is to get a man back to duty as quickly as possible. In connection with the work done at this hospital, there is no idea of dealing with the man as though he were to form one of a class to demonstrate precision of massed movements for a gymnastic display.

If more medical officers were to learn the use of simple apparatus, and realise how easily they could apply their know- 


\section{GYMNASTIC TREATMENT FOR}

ledge as soon as a man's wounds were healed, there would accrue an enormous increase of men available for reinforcements in the fighting line. A very little ingenuity would enable them to apply their knowledge at hospitals where no gymnastic apparatus was available, to tables, chairs, doors, walls, staircases and banisters, as I have often done in years gone by.

The best book for any one wishing to study the subject and become familiar with movements that can be readily adapted to the purpose in view is Physical Education, by W. Maclaren. The truism that no branch of our profession can be learnt from a book only applies with no less force but perhaps more to the present subject. The book study must be hand in hand with practice, which enables application to be made of methods described in the book, which would not occur to one without practical knowledge. A few moments' demonstration of this in a gymnasium would make the point clear. 
JOINT AND MUSCLE DISABILITIES 45

\section{On Movements Generally}

It may not be amiss to make a few observations based on practical experience regarding exercises generally. I would make the broad statement which of course, like all such, is subject to qualifications, that there is no more, or very little more, difficulty in applying ordinary simple gymnastic movements to a partially disabled man than in teaching an ordinary sound man. The sine qua non is that the medical supervisor must know what to do and what it feels like to do it, and be able to direct his gymnastic instructor.

Though a practical knowledge of a few simple things is enough to enable a medical man to treat a man's disability to a point when he can be passed on to his military trainer, the point must be emphasised that it is most desirable that the medical officer should be able to demonstrate a great deal more than he is going to ask a patient to do. This has a considerable moral effect. The greater the 
range of experience of the medical supervisor, the more capable he is likely to be of selecting elements of various exercises and of making them applicable to disablements, and of providing the variety of movement essential in connection with the psychological aspect of treatment of disabled men. The want of this experience on the part of many members of the profession has already been noted, and is the cause of the neglect of the cultivation of simple voluntary movements which would produce markedly rapid results, and of the relegation of many patients to the care of the manipulators of machines.

Where some movement is desired in a disabled limb, always have the movement performed first by the sound limb, and when the man has grasped the movement, then begin to apply it to the disabled one. Furthermore, during the entire course of treatment, the movements should be performed by the sound and disabled limbs acting together or alternately. There 
are physiological reasons for this, but this note is devoted only to practical points. It is common knowledge to gymnasts and professional acrobats that repetition of what you can do helps you to attain that which you could not do. The same applies to disabled limbs. The use of the sound limb helps the disabled one, and the performance of possible movements by the disabled limb helps those that seem impossible for the same limb. It is difficult to illustrate this in writing, and it is a point that needs to be practically demonstrated in order to be realised. It may help when I say that when performing movements with Indian clubs, I found a difficulty in repeating a movement on one side, and that mastery has only been attained by frequent repetition on the other side. In such cases assistance is often obtained by exercising in front of a mirror. This enables one to follow the movements on the good side and to correct them on the bad side. Though this method is not generally applicable, 
opportunity may occur in individual cases where it could be applied in the treatment of both disabled officers and men.

It is difficult to work with cold muscles. The best way to get the muscles flushed is by general exercise of the whole body. This facilitates exercise of the disabled limb owing to the increased determination of blood to the muscles. The alternative is a preliminary hot bath, either general or locally to the disabled limb, which renders any physical work much easier. This alternative is not practicable in all the conditions under which thousands of disabled men have to be treated all over the country. The drawback to laying much stress on the comfortable feeling and freedom of movement produced by a hot bath is the danger of the idea being engendered that it is the essential part of the treatment; and worse still, to engender the idea that unless such means be available there is no use trying to do anything. It is common to see radiant heat applied locally as a convenient alter- 
native to hot water, and this comes to be looked on as the essential part of the treatment, whereas it is only an auxiliary, and one that I have known continued for weeks and months with no result, and when the auxiliary was withdrawn and the man set to perform voluntary exercises of his whole body, as well as the disabled limb, function was recovered rapidly. Where these subsidiary means are not available, there is no need to postpone what is really the bed-rock of the treatment, such voluntary movements of the disabled limb as are possible, assisted by voluntary movements of the sound limbs.

What must be emphasised in promoting recovery of a movement is that the movement should not be repeated more than two or three times without alternating it with the opposite movement. Bringing the opposing muscles of a movement into action facilitates the performance of the movement desired. For instance, every gymnast knows that a 
powerful movement of flexion is facilitated by first extending the antagonistic muscles. Again, in cases of musculo-spiral paralysis in which the hand has been kept in a fully extended position, great help can be afforded by giving exercises which bring the flexor groups into action. The flexion muscles can be exercised with the wrist maintained in an extended position, and as their efficient action depends on the synergic action of the extensors, the impulse from the motor centres is tending all the time to stimulate the latter to action. This fact is mostly ignored in the use of pulley and wrist machines, on which one sees a man continuing to perform one monotonous movement of pronation and supination with no alteration or variation of the position of the limb. For each one movement in the disabled direction, several should be performed in a sound direction. A man was admitted to this hospital who was not considered by a medical officer to be capable of doing work in a gymnastic class, and so was 
JOINT AND MUSCLE DISABILITIES 51

put on to a pulley machine. On the second day he got so bored with the monotony that he appealed to me and asked to be allowed to join the other men whom he could see performing active varied exercises. He did so, and promptly illustrated the fact that a man who can use a pulley machine can also have ordinary and more enlivening movements adapted to his needs.

In an establishment where a number of men are under special treatment, experience shows that there is no need to differentiate the men to any appreciable extent into arm and leg classes-in fact, there is a disadvantage in so doing. A man cannot go on performing arm or leg exercise alone for any time, so all the exercises should be alternated. If a leg case cannot do the exercises that arm cases or other leg cases can do, the instructor is there to help the man through. Of course, there are certain cases which require a more frequent repetition at suitable intervals of certain special exer- 
cises. Such men fall out of the line at such intervals and perform their own special exercises. This system of working classes can be seen in operation at this hospital, and the value would be at once appreciated after a few minutes' personal observation of the work in progress.

\section{The Hand Bag}

One very common result of an injury to the forearm or hand is an inability to grasp with the hand, a condition which may or may not be accompanied by loss of wrist, elbow, and shoulder movements. The quickest way in which to regain any of the deficient movements is to exercise the whole limb at the same time. A man may be sound in every other respect, but if he is unable to grasp a rifle he is useless as a fighting unit. Obviously, then, it is well worth paying particular attention with the object of enabling him to regain his power of grip as speedily as possible. 
Take, for example, the case of a man who from functional paralysis or other cause can only just move his fingers. Such men have come here who have had months of treatment by massage, radiant heat, faradism, etc., without any benefit having been obtained. The aim in such cases is to encourage voluntary action. The patient must have some form of apparatus that he can use with his limited power, and something which will enable him to utilise even such limited power as a just perceptible flexion of the terminal phalanges of maybe only one finger. At this hospital very rapid results have been obtained in such cases by getting the man to put his hand on the greatest circumferential surface of an Indian club of the Burrows pattern and then move the hand up and down trying all the time to grip the club; in the event of his not being able to keep in contact with his whole palmar surface to move it up again until he could, and to continue the movement, using both hands. As the club is resistant 
it does not offer that sense of having accomplished something which is an important psychological aid towards recovery in a weakened man. Accordingly the idea presented itself of having an appliance made of a similar shape to the Burrows

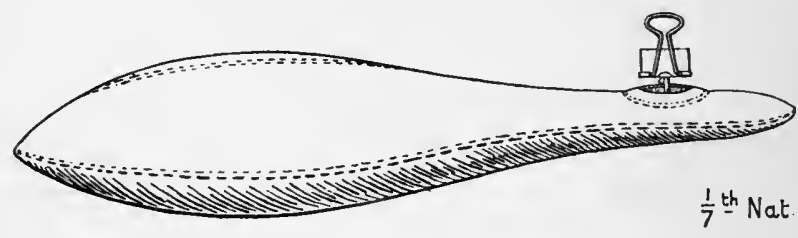

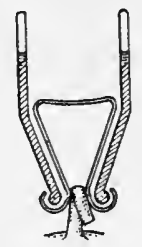

SECTION OF SPRINC

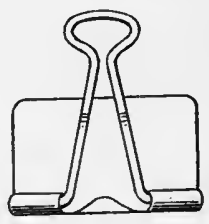

ELEVATION

Frg. 1.- Hand Bag.

club, but of a flexible nature. This was made by Messrs. Spencer, Heath \& George, and registered by them under the name of "Abacot." It consists of an indiarubber bag covered with leather. It can be inflated to any desired degree. In using it, the man becomes conscious of increasing 
power by the extent to which he can indent the bag and of the smaller circumference he is able to grasp. This appliance also enables advantage to be taken of the sensory stimulus obtained by the whole palm and palmar surfaces of the fingers being in contact with the bag. In reeducating the grip, flexion and extension of the wrist and the movements of pronation and supination, the first movements should be practised with the arm hanging and the forearm midway between pronation and supination. By so doing there is the advantage of mechanical power.

When the movements are performed with the limb free, they can be performed alternately, and all the muscles of the limb exercised at the same time by placing it in different positions in relation to the body. The advantages of this procedure applies particularly to pronation and supination, inasmuch as the movements are assisted by the rotations of the shoulder joint. Pronation and supination without the assistance of 
rotations of the shoulder joint are comparatively weak movements even in the normal individual.

Some such simple appliance as the "Abacot" bag allows of movements of fingers, pronation and supination, etc., to be performed with the arm hanging or raised to different levels either to the front or to the side, and such levels should be constantly varied.

If such an appliance is not available, dumb-bells of any suitable weights from a few ounces upwards can be utilised in the same way, and the bars of the dumbbells can be adapted to suit varying powers of grasp by wrapping cloths round them.

\section{Indian Clubs}

A simple and effective method of reeducating the movements of the fingers, wrist, elbow, and shoulder-joints are Indian clubs. They are applicable to such disabilities at a period before a man could be put on any other exercise. An ines- 


\section{JOINT AND MUSCLE DISABILITIES 57}

timable advantage is that the movements follow each other: pronation followed at once by supination, flexion of the wrist by extension, and the circumductory movements of the shoulder. Another advantage is that the man can be given an interest in his movements by watching the club so as to maintain it at the proper position throughout the movement.

The best make of club is the Burrows pattern, this being hollow and shaped as in the diagram. For the purpose of re-educating the grasp; a pattern is being made at my suggestion by Messrs. Spencer, Heath \& George, with interchangeable handle of various sizes.

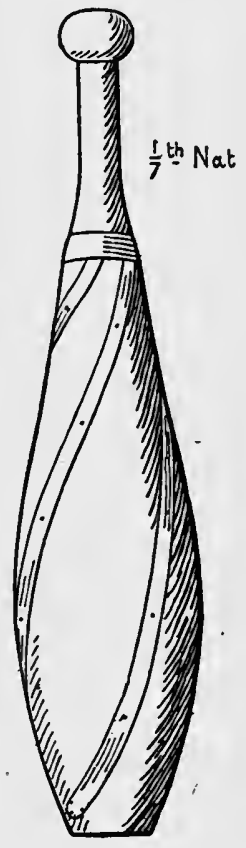

Fig. 2.-Indian CLUB.

The value of the application of clubs was strikingly illustrated by the case of an officer who had had his sick leave 
extended a considerable time on account of stiffness of the right shoulder, the result of a gunshot injury. He had been told by a prominent orthopædic surgeon that nothing more in the way of active treatment could be done and that Time was the only cure. He was given simple movements with the clubs, which at first, if extended beyond a certain point, produced pain. In a few days he began to be interested in the number of times he could repeat the movement without any pain. By the end of a month he was swinging the club round both inwards and outwards at full stretch of the arm.

As Indian clubs have such a valuable application to those conditions and are superior to any machine, it is worth while to give as clear a description as is possible without practical demonstration of the first elementary movements. Indeed they are all that is necessary, because once a man can perform them he is capable of doing other things, and the object is not 
to teach him to swing clubs, but to recover the use of his limbs.

First the club should be held loosely with the fingers and thumb as much round the handle as the disability will allow, and in all positions the club should be kept in a line with the forearm. Every one, disabled or otherwise, will at first let the club sag so that the end of the club lies behind the line of the forearm. When the club is moved above the head with the club in this faulty position, there is a loss of sense of the position of the club and the direction it has to take, and if the man is told to make an outward circle he will almost certainly make an inward one or none at all.

Club-swinging is a good training for co-ordination and muscular sense.

There are four angular movements which can be made outwards or inwards, and two circular movements made outwards or inwards, and the most complicated club exhibition consists of combinations of these angular movements and 


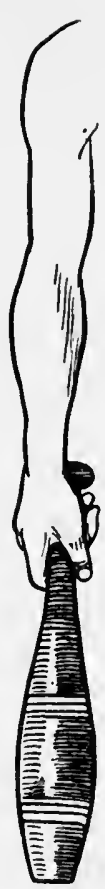

circles. The sketches drawn from life by Gunner A. H. Lock, Royal Horse Artillery, a patient in hospital, show the four angular positions made by moving the club outwards, thus describing a large circle.

In Position 1, the hand is midway between pronation and supination.

As the club is carried to the position of Position 2 the hand is pronated; then in passing to Position 3 straight above the head, the hand resumes the midway position, and in passing to Position 4 is supinated. In passFra. 3.- ing again to Position 1 the hand Position I. resumes the midway position.

In performing the movements inwards,

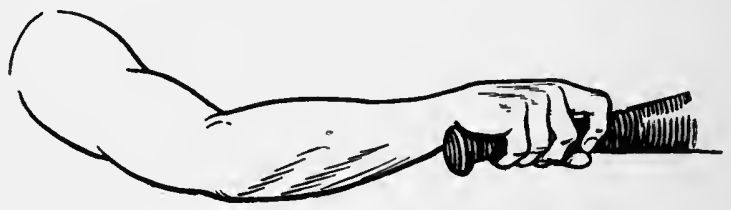

Fig. 3.-Position 2. 


\section{JOINT AND MUSCLE DISABILITIES 61}

the Position 1 position is the same; the club is then carried to Position 4, during which the hand is supinated; then to Position 3 above the head, when the hand is again midway; then in passing to Position 2 it becomes pronated, and at Position 1 resumes the midway position.

A patient can be helped to attain the positions, and then can also be helped to go through them with a swing. The advantage of the swing is that when the club is in a vertical position and it is allowed to drop by its own weight, it

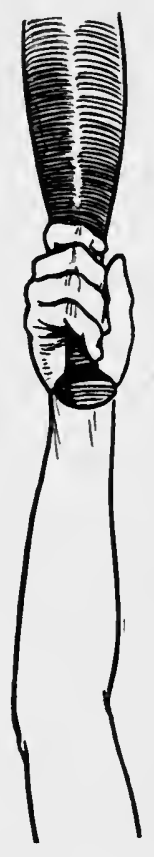

FIG. 3.Position 3. assists the next upward movement, and as improvement takes place, the rate of swinging can be increased. In so

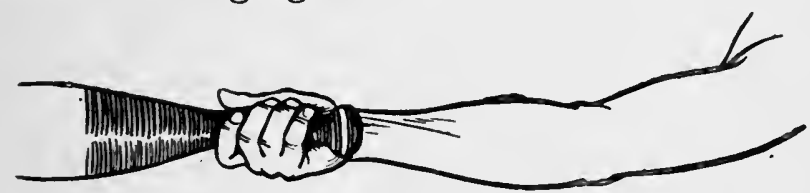

Fig. 3.-Position 4. 
doing, the club should be kept in its proper plane, the point of the club being directed straight up and down and to the sides. In so swinging, the arm should not be carried behind the plane of the body. The club should not be pulled down in the downward movements, but allowed to fall, and on this depends the essence of good club-swinging which gives a spectator the impression that the clubs are moving the arms and not the arms the clubs.

Though the short circles can be made outwards and inwards all round the body and limbs, two positions in which to do them are sufficient for the purposes in view, e.g. in front of the body and behind the shoulder. The circles can be performed, if necessary, by assistance, and here again at the risk of repeating myself I must emphasise the advantage of the voluntary performance even of a fraction of a movement.

The short circles are performed outwards or inwards. Both start the same as shown in Position 1 (Fig. 3) sketch of the long 
circles. To perform outward circles, the hand is pronated and the club raised to Position 2 (Fig. 4), in which the handle of the club is supported on the proximal phalanx of the thumb as close to the metacarpo-phalangeal joint as possible. The club is then raised to the vertical

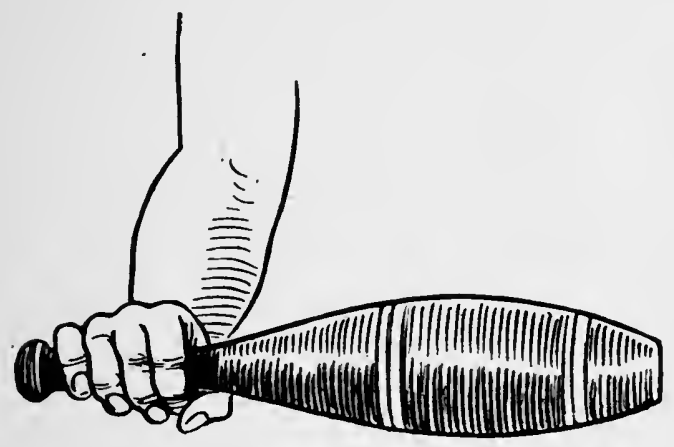

Fig. 4.-Position 2.

position, the hand coming to the midway position and the elbow being slightly bent (Position 3). The club is then carried to Position 4, in which the hand is supinated, the handle of the club resting in the fork between the thumb and forefinger. The club is then carried again to Position. 1, the hand passing to the mid-position. 


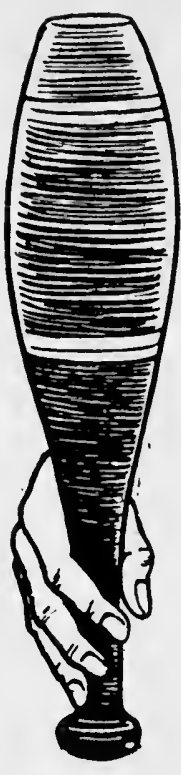

Fia. 4.Position 3.

To perform inward circles starting from Position 1, the hand is supinated, the club carried to Position 4, and the movements are the exact reverse of the outward circle.

To perform the outward circle behind the shoulder, start from the position in which the club is extended above the head as already shown in Position 3(Fig.3) of the large circle; the elbow is bent, the club allowed to fall outwards until it hangs vertically behind the shoulder, the elbow being kept at the

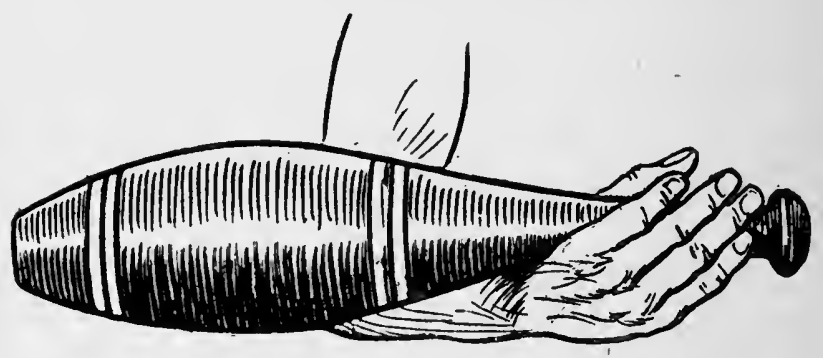

Fig. 4.-Position 4. 
level of the shoulder during the movement; the hand becomes supinated, the grasp of the fingers being relaxed to suit the altered position of the club; the club is then carried behind the shoulder pointing to the left, the hand becoming pronated and the extended position above the head resumed as the elbow again becomes extended. To perform inward circles, the movements are exactly the reverse. During all the movements of the club the fingers are constantly shifting and varying their position and grip to accommodate them selves to the movements of the club. This constitutes an excellent method of re-training the fingers.

Case.-A man aged 40 sustained a fracture of the left radius by falling into a trench on September 5th, 1917. The arm was kept in splints for two months, and when these were removed he had treatment by massage and electricity. On admission here, on November 5th, 1917, the left arm was fixed to his side, the elbow bent at a right angle, and 


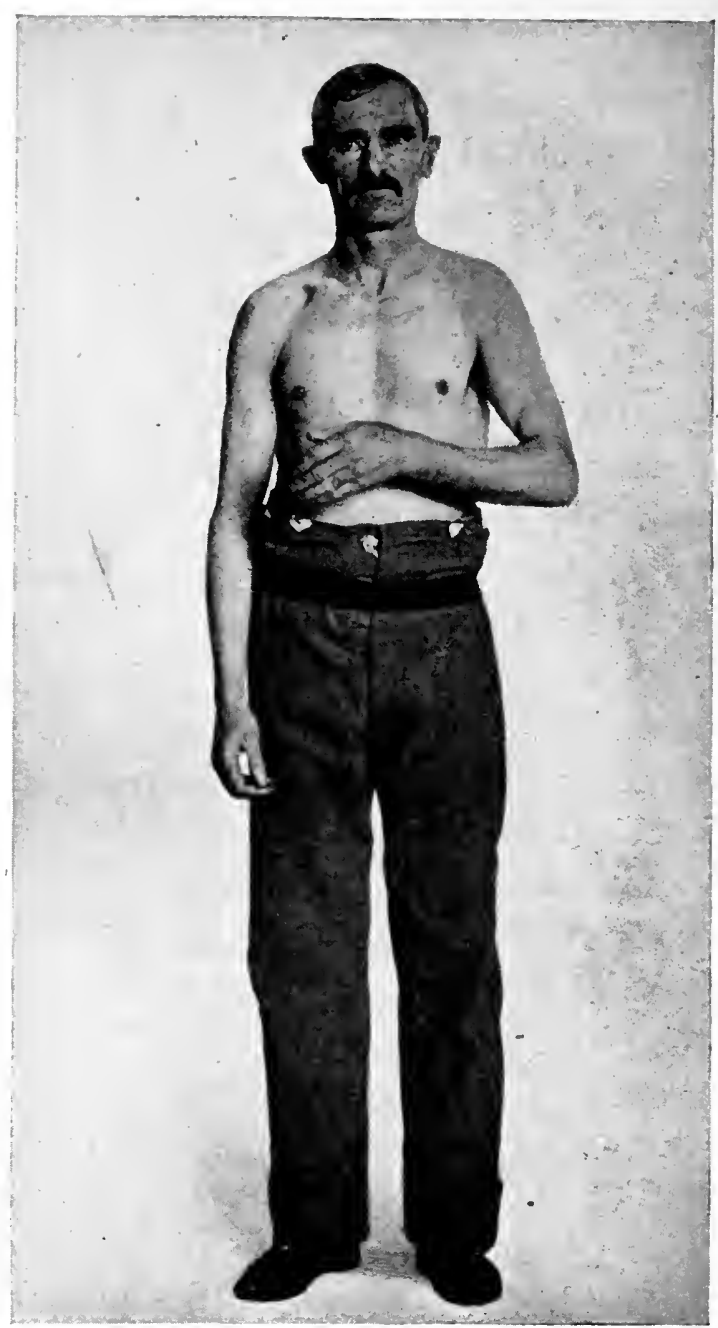

Fig. 5.-Condition on Admission. 
JOINT AND MUSCLE DISABILITIES 67

there was complete fixation of the shoulder, elbow, wrist, and finger joints. $\mathrm{He}$ was treated by exercises on the hand bag, nautical wheel, and Indian clubs, and on November 28th, 1917, was using all the joints freely. A fortnight later he was climbing a rope. Figures 6 and 7 show how the movements of pronation and supination were assisted to recover by use of an Indian club.

The application of the use of the club in an extreme case can be well exemplified by the case of a jockey who enlisted in the 19th Hussars in the early days of the war. His horse fell with him and injured his back. He was in hospital for twelve months and was treated by blisters, ionisation, and massage, and was eventually invalided. He came here for a pension board, and had taken twenty minutes to hobble about three hundred yards from the tramway to the hospital with the aid of a stick, and in pain all the time. He was unable to straighten his back and could not raise his arms 


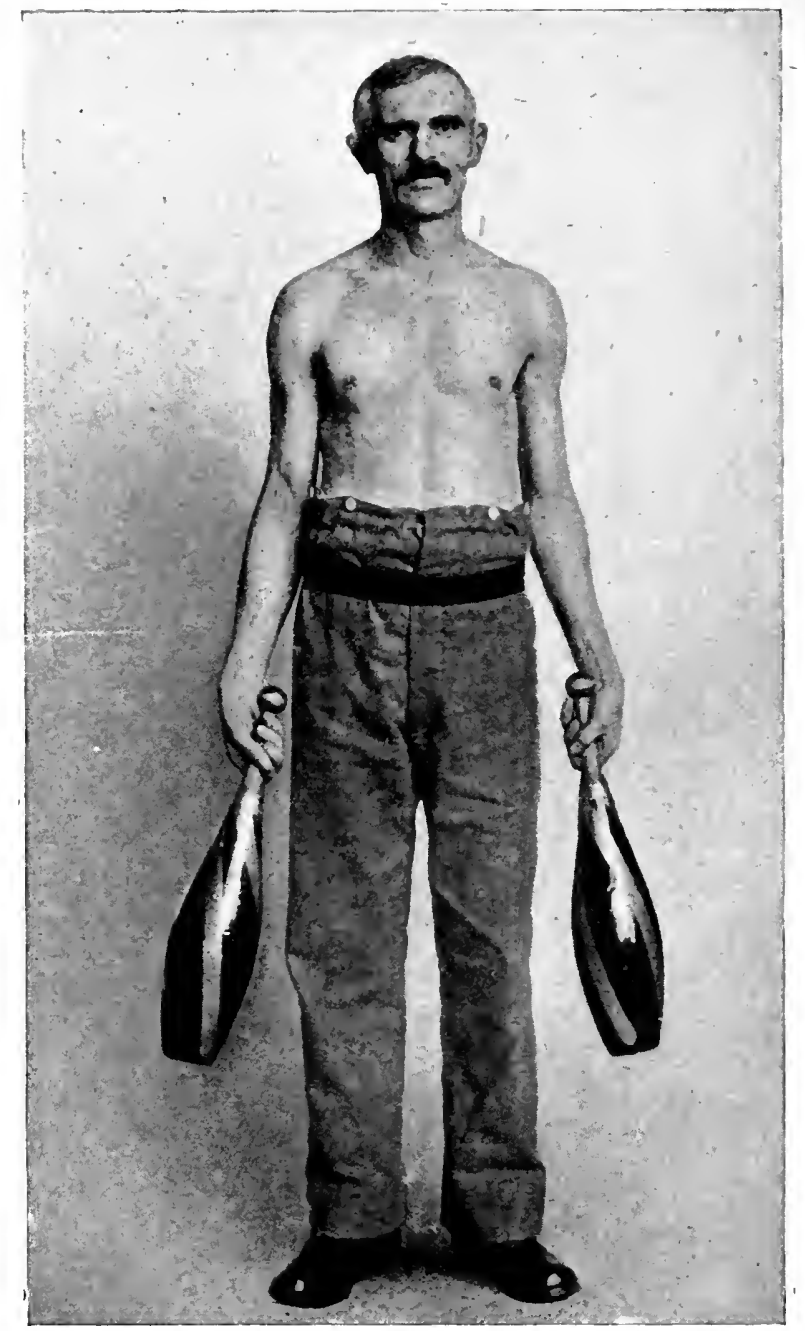

Fig. 6.-Patient supinating Left Hand One Month AFTER TR EATMENT. 


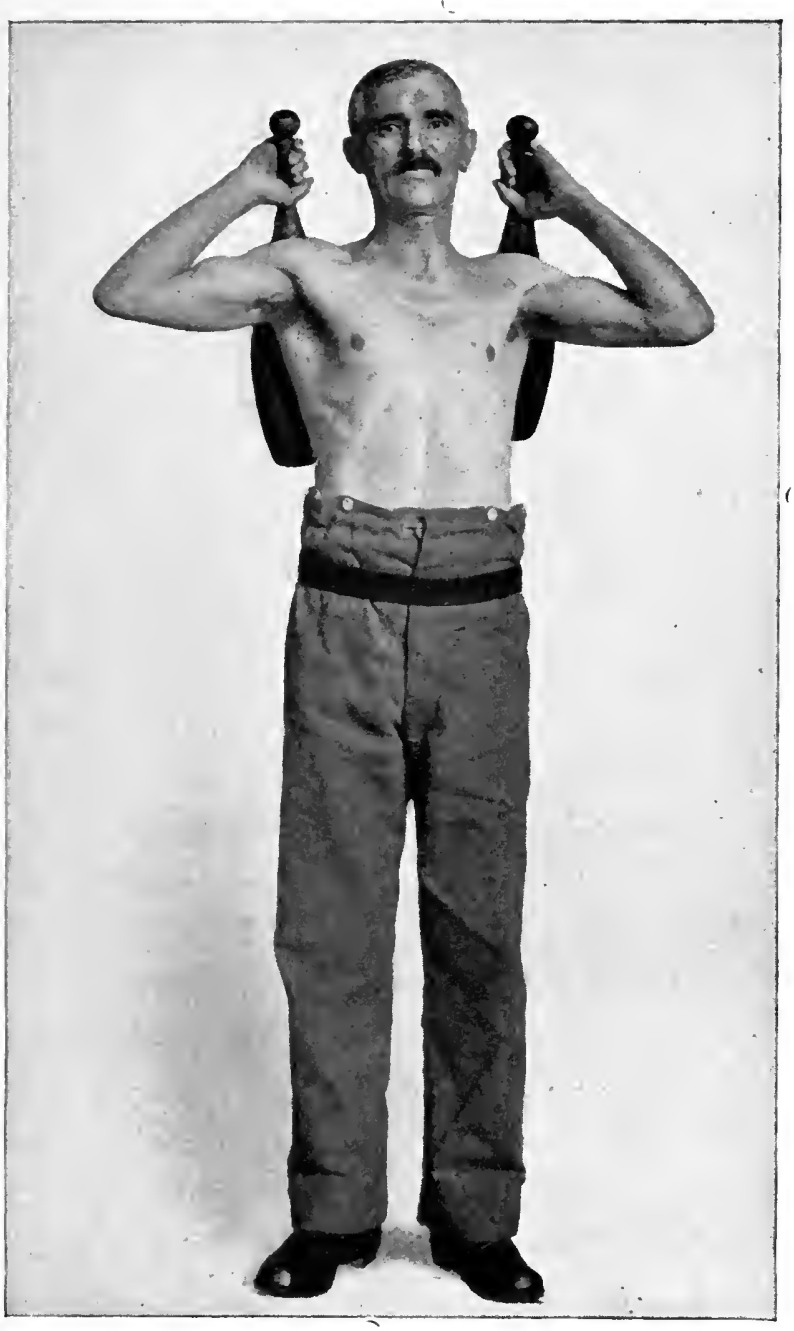

Fig. 7.-Patient performing Short Circles behind Shoulder Six Weeks after Treatment. 
above his head owing to the pain it caused in the sacral region, especially on the left side. There was great tenderness all over the left sacral region and of the left sciatic nerve. He was depressed and said he would do anything to get better, as his life was a misery to him. I commenced treatment by getting him to hold a club in one hand and swinging it backwards and forwards only to the extent of an inch or two; when this was done with the right hand, it caused great pain in the left side as soon as that group of erector spinæ muscles came into action to balance the forward move of the club. I also had him helped to a standing position on the beam and had him supported on it so for a few seconds at a time. Progress was slow but consistent; and though it was a few weeks before he could hold a club above his head, in three months' time he was able to perform combination movements above and behind his shoulders; and could walk a mile without pain. 


\section{The Skipping-Rope}

A simple appliance which can be made great use of alike in leg, arm, and hand cases is the skipping-rope. The movements of turning the rope ean be exaggerated so as to get an increased range of shoulder, elbow, wrist, and finger movements, and if only slight movements of these joints are possible, the skipping can be done and the movements of the whole limb are co-ordinated in a natural way. It has the further advantage of providing general exercise for every limb, and promotes the action of heart and lungs necessary to a man who perhaps has been in hospital for several months doing no physical exereise.

The use of the skipping-rope can be made more interesting and indeed more efficacious by a few simple dance steps which I know from experience are no more difficult to teach a man with a stiff shoulder or wrist than a man with full use of all his limbs. 
For exercise of the lower limbs only and for the effect on the heart and lungs, skipping can be applied to a class of any size by a long rope being swung by a man at each end, and four men at a time can easily.use the rope.

Wrist Rollers and Pulley Machines

Wrist rollers have either weights attached or the resistance is made by friction. This apparatus should always be fixed so that it can be used vertically, because when fixed horizontally, as is usually the case, the rollers have to be grasped with the hand in pronation or supination, thus causing a loss of mechanical power. There is no reason why a disabled man should be placed in a disadvantageous position to recover function. The greatest power of grip obtains when the hand is midway between pronation and supination. The frictional machines made by Messrs. Spencer, Heath \& George allow of being fixed vertically. They have the 
additional advantage of having three thicknesses on the roller, and when used in the vertical position, movements of flexion and extension of the wrist can be performed alternately. When they are used in the gymnasium here, two rollers are used, one for each hand.

A great fault in all pulley machines and wrist rollers that are worked on handles is that the handles are too small for any man who has not got a full grip. The handles should be so made that they can be made adaptable to the man's grip. A man is handicapped in performing any movement unless he can feel that the apparatus he is using is in close contact at all points with the grasping surface of his hand.

Both sets of machines have the great disadvantage of monotony of movement and want of variation. A man is set at the machine and told to do so many movements of one kind which a sound man would not be able to perform without becoming bored, and in the case of a 


\section{GYMNASTIC TREATMENT FOR}

disabled man boredom prevents an amount of necessary volition being put into the movement, a point which is so vital in dealing with these cases. I have often observed this when watching men at these machines.

The pulleys of these machines constitute in themselves a great drawback. The work done is more apparent than real, and it is easy for any one not familiar with the various kinds of physical work to be deceived as to the energy displayed by the man and as to the energy of which he is capable. This has been observed here on many occasions. It is infinitely of more benefit to a man to use a halfpound weight in his hand, in which position the weight is near his own centre of gravity, than to use many times the weight by means of pulleys.

By all means let all the good be got from the use of these machines that is possible. They provide a means of obtaining some movements in the absence of other means, and when no one is 
available with knowledge of better means; and as charts of exercises are published for the pulley machines illustrating almost every possible exercise that can be performed on them, their use can be learnt very easily by any one in a short time. It is pathetic to see men, as is not infrequently the case, using a pulley machine or having their limbs moved by a mechanical device, reading their letters and newspapers.

\section{The Vertical Rope}

The initial positions of climbing a rope with the hands and feet are applicable to disabilities of the upper and lower extremities, whether affected by weakened muscles, stiff joints, or scar tissue, and at the same time exercise the back and abdominal muscles.

The advantage of rope climbing applies to other apparatus on which climbing can be performed, that of being able to use each side of the body as circumstances 
require or allow to a greater or less extent. When the limbs of one side are weak, they obtain assistance from the sound limbs. It is probable that no one, medical or otherwise, will appreciate this till he has climbed various apparatus, and if the realisation of this fact were better appreciated by the profession there would be less futile treatment carried out.

As this use of the rope cannot be usefully applied without a knowledge of the correct position, every one responsible for the physical treatment of disabilities should makc it his business to learn it, as otherwise his utility is at a heavy discount for enabling men to recover the use of their limbs as speedily as possible.

The mistake invariably made by any one who is asked to climb a rope is to jump on to the rope with bent arms, one consequence being that he gets no hold of the rope with his legs and feet, the rope hanging loose between the upper part of the thighs.

The arms should be kept at full extent 
until the legs are in the position shown in Fig. 10, and an enormous amount of benefit can be obtained from this position alone.

When the arms are extended as fully as possible as in Fig. 9, the feet are raised from the ground, the knees then drawn up, the feet crossed over the rope, which is grasped between the knees and feet.

If a man is unable to lift both feet off the ground at the same time when hanging by his arms, the movement can be simplified by raising one foot and placing it against the rope with the knee on one side and the foot on the other side of the rope. Then the other leg follows in the same way as in Fig. 10.

The man then bends his arms, straightens his legs, carrying them to the front, and then assumes position shown in Fig. 8. If he is unable to climb, he then again extends the arms, retaining the legs and feet in position, resuming the second position as in Fig. 10. This can be repeated according to the man's capabilities. 
If a man is unable to extend both arms to the full stretch, he grasps the rope as high as he can with the disabled one, and alternates one hand above the other as his capabilities allow and according to the progress made.

A disabled man can be assisted by the instructor through every movement concerned in the three positions shown, and even if the instructor has to assist him through nine-tenths, the remaining onetenth which the man has to do himself does what has been evident that weeks and months of other methods of treatment have failed to do.

For the purpose of enabling a disabled man to recover the functions of his limbs, only one or two methods of climbing need be adopted, though for men who have full use of their upper limbs they may be allowed profitably to climb by the hands without the use of the legs as they like and can.

From Position 3 (Fig. 8), one or other of the following methods of climbing can 


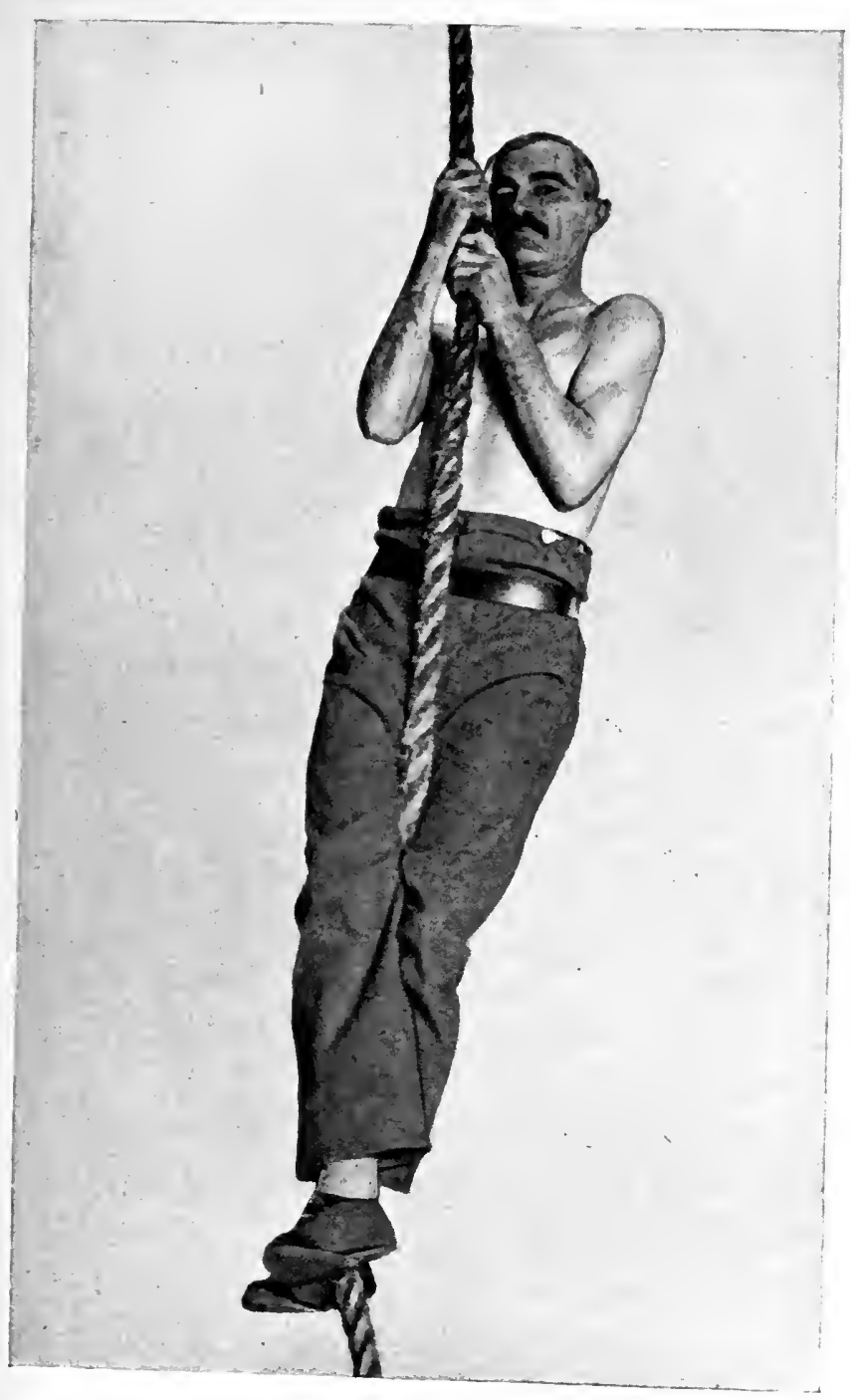

Fia. 8.-Rope Climbing, Position 3. 
be adopted, and they may be alternated with advantage, the method adopted by gymnasts being largely a matter of habit. The effect of these exercises is enhanced by introducing variations.

From the same position the arms are again extended to full possible extent, one following the other, and the grasp of the rope with the knees and feet is relaxed, the knees drawn up as in Position 2 (Fig. 10) and a fresh grasp taken of the rope with the knees and feet with the arms still extended; the arms are then bent and legs straightened as before.

In descending, the hands are placed one above the other opposite the chest, and the body lowered to the full extent of the arms, the legs being kept straight with the rope between the feet.

It is convenient here to note that in climbing a rope or any other apparatus, the limbs of the sound side of the body can be utilised to the greater extent in the ascent, and those of the disabled side in the descent, and improvement is 
shown by the extent to which the man can climb with the disabled side leading in the ascent. Before ascending the rope or other apparatus, with the weak side leading throughout the ascent, this should be made by each side leading alternately.

Another method starts from Position 2 (Fig. 10). The rope is held fixed between the knees and feet. The body is pulled up by the arm and trunk muscles, the hands passing alternately one above the other, during which the legs straighten. Position 2 is again obtained and the upward movement repeated.

Combined with other apparatus, the use of the rope enables extension of the shoulders to be obtained more rapidly than by any other method with which I am acquainted.

Case 1.-The man depicted in Figs. 9 and 10 was wounded on August 16th, 1917, sustaining a compound fracture of the head of the humerus. Fig. 11 shows the extent to which he could extend 


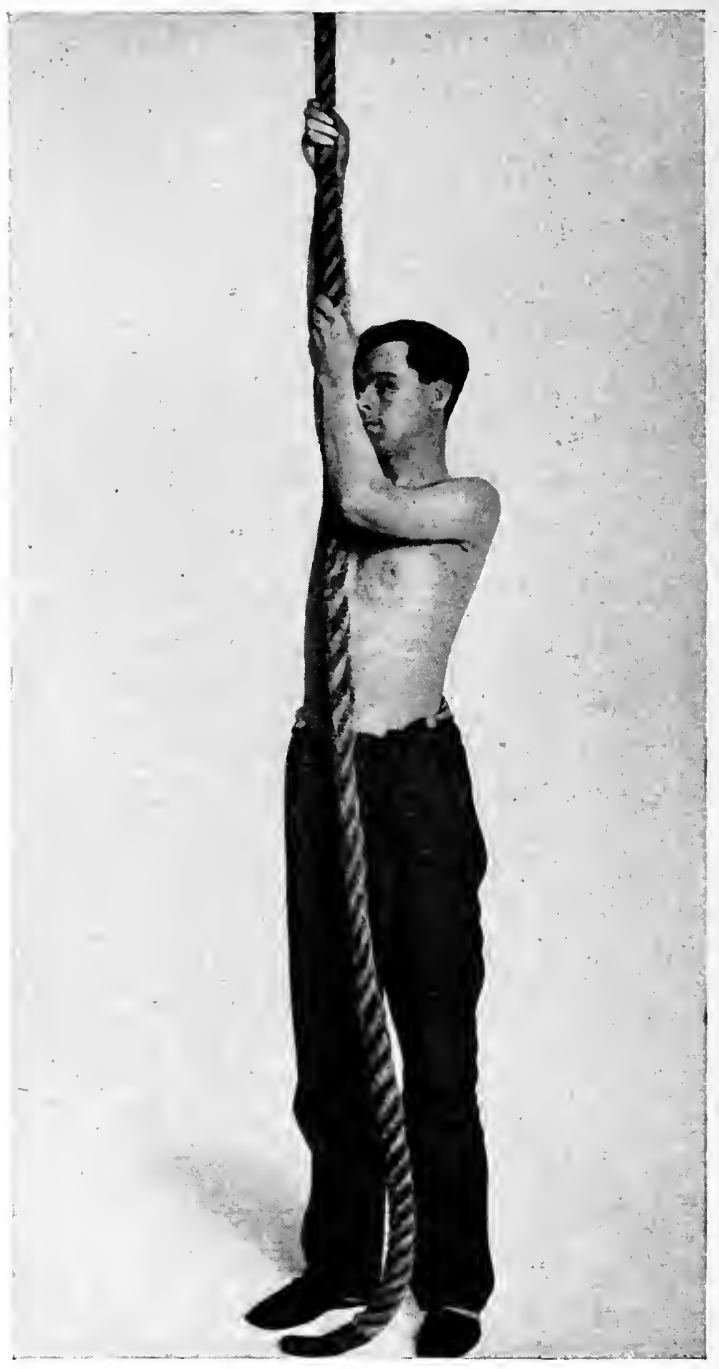

Fig. 9.-Rope Chimina. 


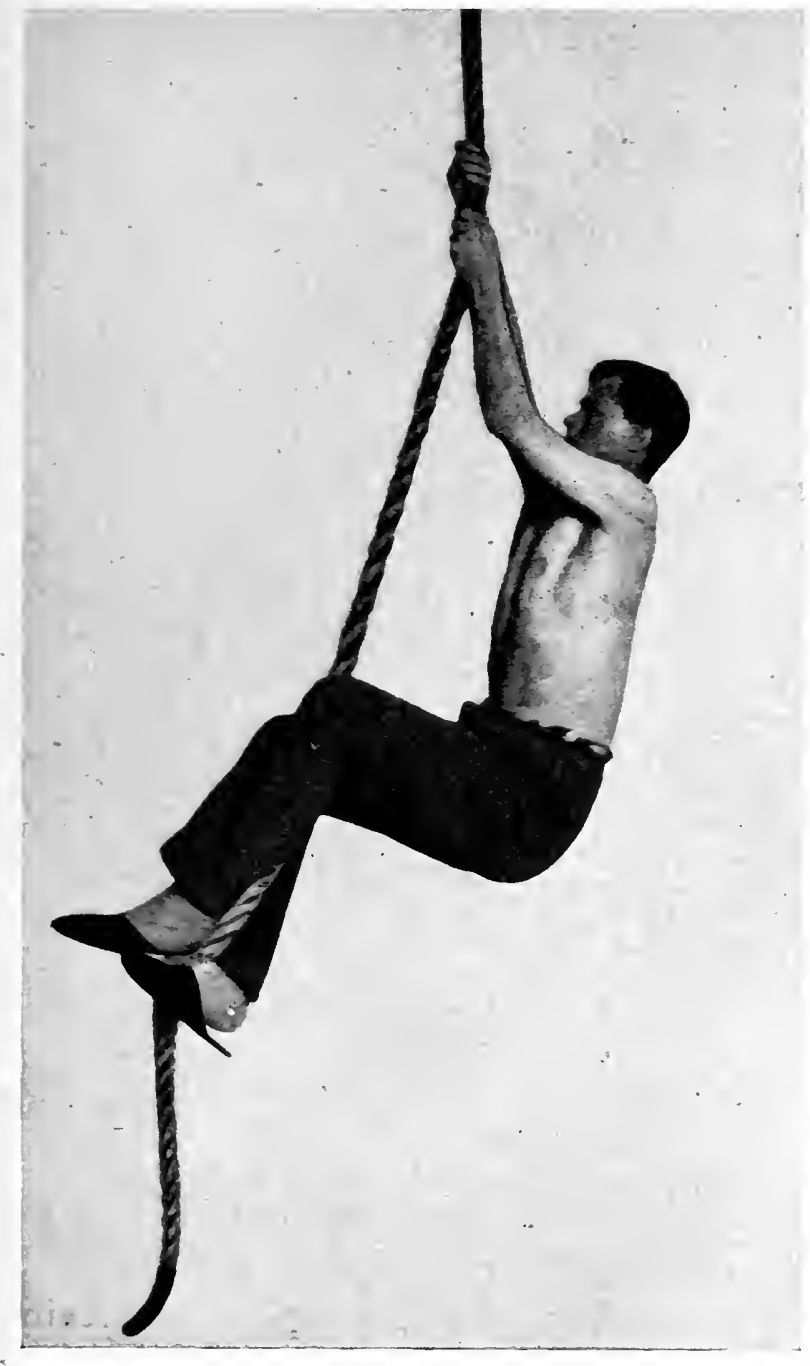

Fig. 10.-Rope Chimbing, Position 2. 
the arm when frec. 'The case well exemplifies the advantage of gradually using the body weight to obtain extension of the arm; which method can be applied on different apparatus, thus providing a variety of movement, all tending to the one end. He had a month's treatment by massage, and was admitted here on November 20th, 1917. His condition on admission was as follows : There was a scar of entry, 2 inches below the left acromion, and a scar of exit in the upper part of the posterior axillary fold. He could abduct the upper arm to an angle of $55^{\circ}$ and flex it to a right angle. The elbow was flexed at a right angle. There was slight power of rotation. He could only place the back of the hand on the front of the iliac crest. His grip would not allow him to hang on the rope. He was given exercises on the nautical wheel and wall-bars for two weeks. By the end of that time he had power to hang on the rope and attain Position 2 (Fig. 10), and was exercised in 


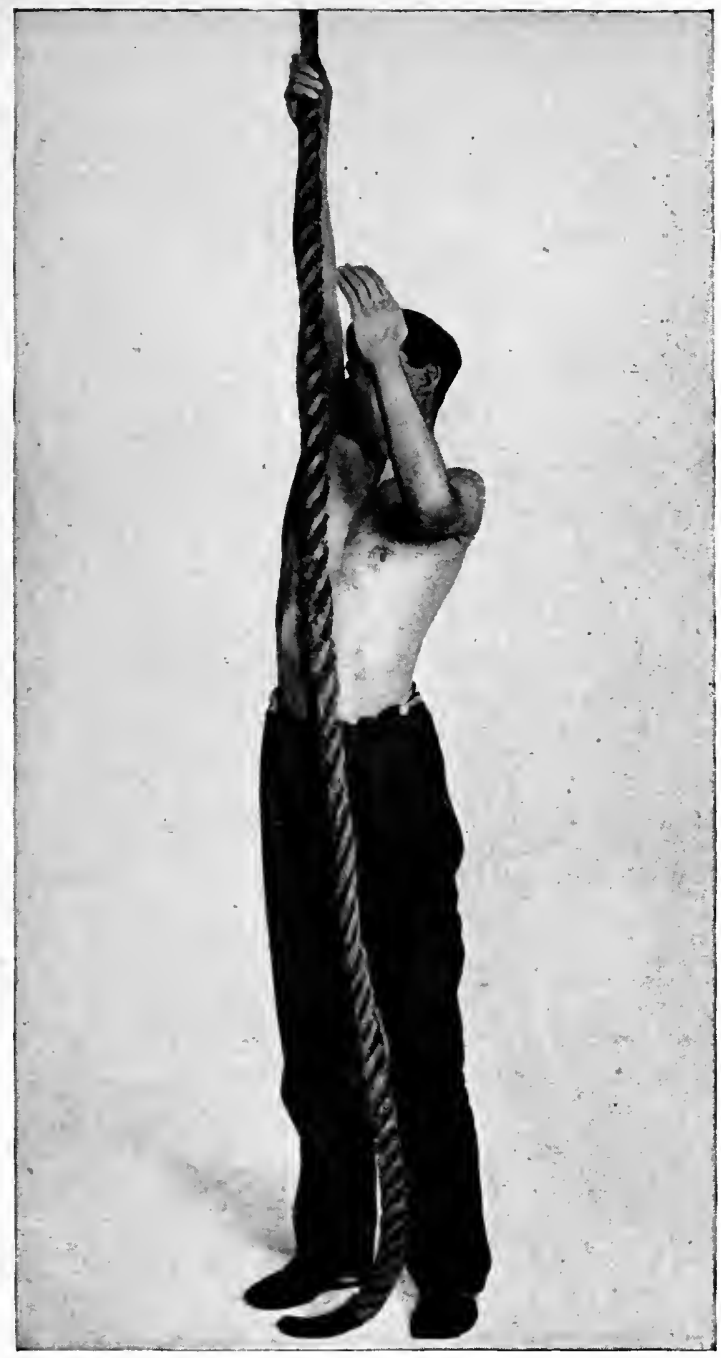

Fig. 11.-Extent of Free Movement after Two Weeks' Preliminary Treatment on Nautical WHEEL. 
that position as noted above. At the end of a month he could climb to the top of the rope, he could place the back of his hand on the vertebral spines, and his elbow had gradually become almost fully extended. The man shown in Fig. 8 illustrating the third position for climbing, is the same man as is referred to under the section dealing with the Indian clubs (Figs. 5, 6, 7).

Case 2.-A man had his hand scratched on barbed wire in April 1917. Sepsis supervened with resulting extensive cellulitis. After the wound had healed, he had treatment by massage and electricity for three months, with no sign of improvement. At this stage he had complete loss of voluntary movement of the left arm and hand. As unfortunately the man had been told that it would take a long time to recover he was in a thoroughly disheartened condition. He was handed over to Lieutenant E. Stafford, who had instructions as to dealing with such cases and who displays originality 
in carrying them out. The case is an excellent illustration of what I havc emphasised all along, namely the value of utilising a man's sound limbs to enable function of a disabled one to be restored, thus stimulating the motor centres in their entirety. It was obviously impossible to give him anything to do with his left arm alone. Treatment concentrated on the disabled limb had proved futile, and it was a suitable case for treatment by the methods I advocate. Space will not allow of a full description of the procedure, but to commence with, the treatment consisted of setting him an exercise which necessitated simultaneous action of both arms and both legs. The first few attempts were failures, and then the instructor gave a small amount of assistance which was gradually withdrawn without the patient realising it. In a quarter of an hour the first sign of improvement was seen. At the end of a week he raised his arm above his head, though at this time he could not move 
his fingers and had complete wrist-drop. The day after he got his arm above his head he began to have a flickering movement of his fingers. This was cultivated

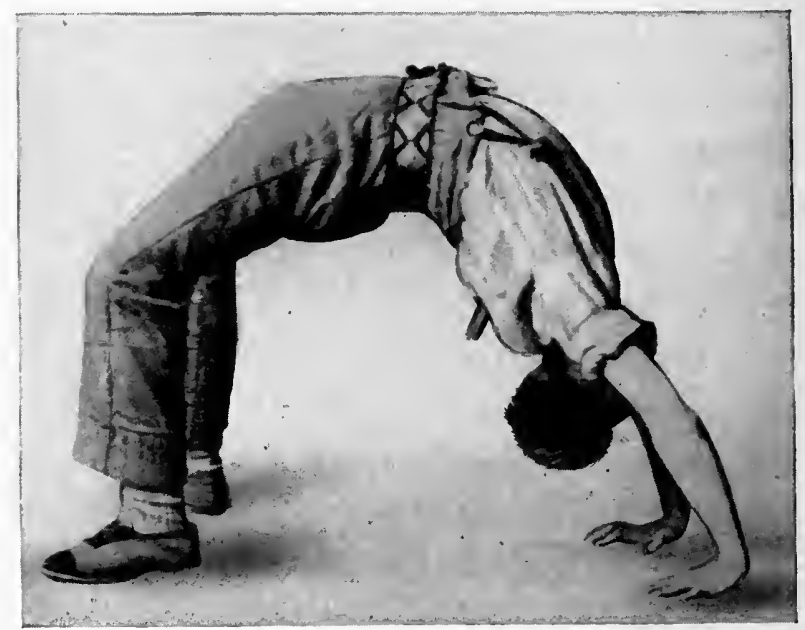

Fia. 12.-Back Bend by Man with Paralysis of Left Arm, after One Month's Treatment.

by use of the hand bag and nautical wheel, and within twenty-four hours he could close his fingers into the palm and extend them fully. The next day he extended his wrist, and the day after he could hang on the rope and could press 
up from the floor from a bent arm position. After this, he took his part in all class work. This man in about a fortnight's time passed from a condition of considerable muscular wasting and of complete functional paralysis of the left arm, where there was defective circulation and blunted cutaneous sensibility up to the level of the middle of the forearm, to a condition of complete and efficient function. Fig. 12 shows a position the man assumed about a month after treatment commenced. He had been able to do this exercise before his disability. It serves to illustrate how men are encouraged to do anything they like of which they are capable.

Case 3.-The following is typical of the loss of man-power consequent on the want of a due appreciation of the application of simple gymnastics :

A man received a gun-shot wound of the left forearm in August 1916. During the succeeding six and a half months he received five months' treatment by 
massage, and was then sent to a command depôt, where he was put on wrist rollers and Swedish exercises for three months. He then joined his depôt and in a few days was again admitted to hospital as he could not use his left hand owing to inability to flex the fingers. He came here in August 1917, when he could just slightly flex the phalangeal joints, but not sufficiently to grasp a rope, and the fingers were very tender. $\mathrm{He}$ was given a hand bag to work on, and was exercised on the rope while the disabled hand was supported round the rope and his feet were supported by the rope being held under the insteps. In a week's time he climbed to the top of the rope, and in a month's time could perform all the exercises qualifying him for discharge to military training.

Another instance: A man had been under massage and electrical treatment for several weeks for paralysis of the left hand, which was complete for all movement, and the man had given up all 


\section{JOINT AND MUSCLE DISABILITIES 91}

hope of recovering the use of his hand. I had the advantage of Lieutenant-Colonel Mott's opinion before doing anything that the case was functional in character. The case was then handed over to the gymnastic instructor with directions as to how to start. By the end of a month he was able to climb to the top of the rope with a good grip.

\section{The Parallel Bars}

The value of this apparatus may be judged when it is said that were a gymnast confined to one piece of apparatus for ordinary purposes, or were a medical superintendent who understood the application of gymnastics to disabilities restricted to one apparatus, unhesitatingly they would both select parallel bars. They can be used above, below, and at the side, and the bars can be used together or singly.

The exercises on them can be adapted to the most accomplished gymnast and 
also to the disabled man who is only just able to move a limb, and can be adapted to all grades between those two extremes. This apparatus is a veritable multum in parvo, and may be said almost to constitute a gymnasium in itself, and for purposes of remedial work of the kind demanded by war disabilities it forms an inexpensive compendium incomparably superior to the many expensive and elaborate appliances advertised.

The parallel bars are adaptable to disabilities of the body from the neck to the toes, and though it might be thought by an inexperienced onlooker that they were only of use to the arms, such ideas could only arise from want of knowledge and would soon be rectified if such a one could be persuaded to perform any of the simplest exercises.

The apparatus allows of almost infinite variation, and what is very important, affords the man an interest in doing something. Here again I must emphasise the bencfit of the men using their sound 


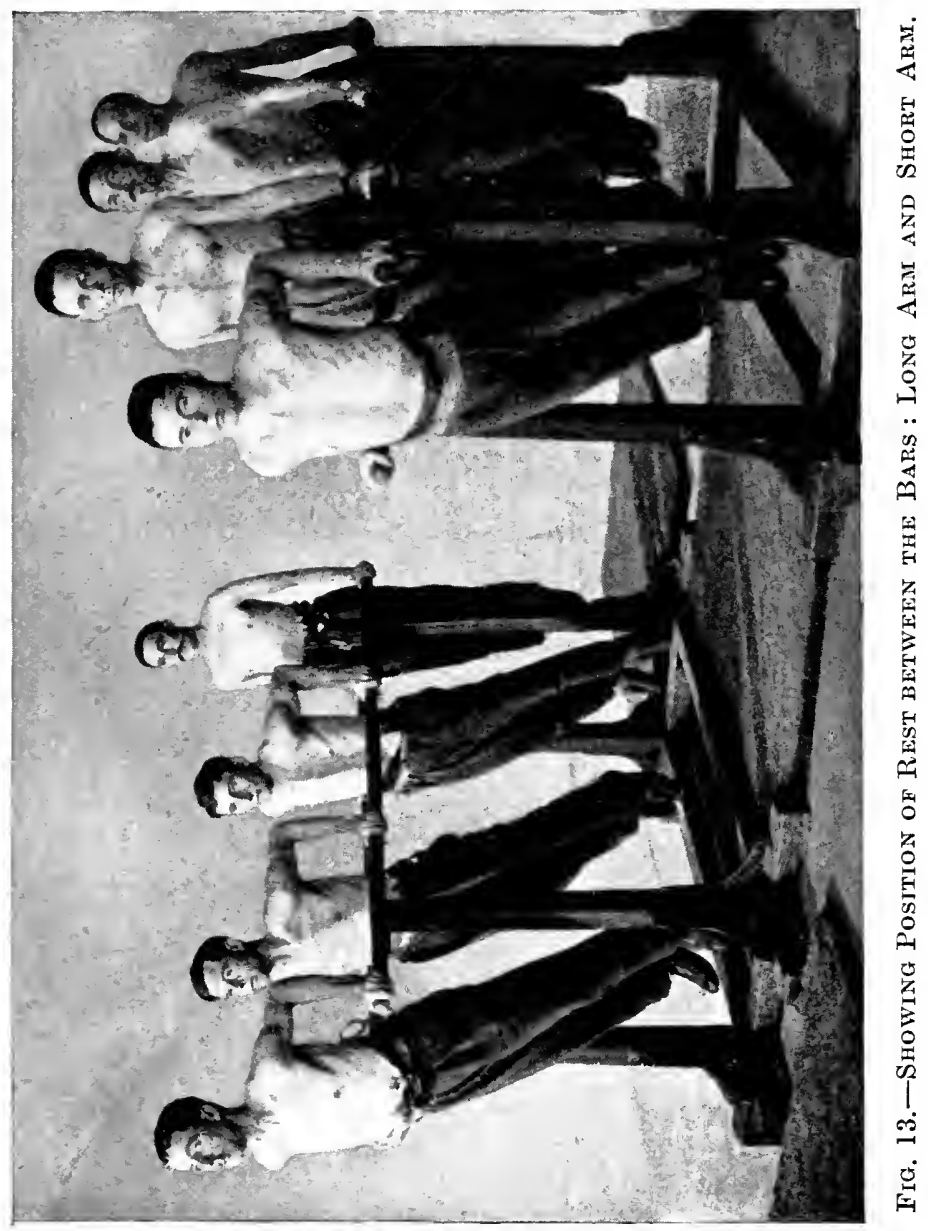


limbs at the same time as the disabled limb is being coaxed back to function. Thus the man is enabled to recover and increase his general muscular power and also the elasticity of his muscles.

The inspiriting effect of this apparatus may be illustrated by the fact that if a lot of children are let loose in a gymnasium, they make straight for the parallel bars, next they make for the ropes.

It is quite impossible to describe the infinite application of simple exercises that can be made to all degrees of disabilities, but a short description of one such will serve to indicate the lines on which to work, but the application thereof must be learnt in the gymnasium.

Take the position known as the "rest" between the bars and which is shown in the photograph of the men with the arms straight.

A gymnast jumps from the ground into this position and stops steady at once. To attain this position involves active use of practically all the muscles 
of the body. It can be adapted to a patient by first placing his hands on the bars and then jumping up from the ground at the same time pressing with his hands, and when he cannot even then get up, it is an easy matter to give him the required amount of assistance. Then when he is up, with or without assistance, he bends his elbows and drops his feet to the ground and gets a fresh spring. This movement can be repeated according to the circumstances of the case.

If the patient cannot bear his weight equally on the arms, he can put more weight on the sound arm till he can do so, and to any one not familiar with the applicability of such an exercise, it would be surprising to see how a patient who on the first day could not bear his weight on the bars unaided will in two or three days not only bear his weight, but perform a march along the bars.

A great advantage of all exercises on the bars is that they supply a means of treating disabilities of the lower limbs, 
whether joints or muscles or both are involved, and the joints are being brought into action in a natural manner.

Take the case of a man with a stiff knee or ankle or with wasted thigh muscles which will not allow him to bear his body-weight with bent knees. Every time he is above the bars, he has to come down again, and when he cannot drop clear on his feet, he can take part of the weight off by retaining a hold of the bars with his hands. As he gains power and confidence, he retains hold with one hand only, and then progresses till he can drop on his feet. Here again assistance can be given him at first in landing.

The variety of simple vaults are very useful for this purpose of treating the lower limbs, and they do not have the disadvantage of monotony of movement, and if the patient's lower limbs only need treating, he is exercising the sound part of his body to advantage at the same time.

The simplest exercises, marches, swings, 
vaults, etc., allow of combinations and great variety and can all be performed with assistance if necessary. This apparatus illustrates the incomparable advantage of the agency of human assistance in performing an exercise over any mechanical device. Such assistance can be given to any part of the body at any required part of the movement, and can be exactly regulated to the needs of the patient and varied from time to time according to progress. This affords encouragement to the patient and enables him and the instructor to appreciate any improvement. This is in striking contrast to the deadening effect of any mechanically devised assistance which is unvarying in its operation, and affords no indication as to how much the man is doing and how much the machine. This is a point which may be difficult of realisation to any one who has not had the benefit of at least an elementary gymnastic training and who has not been assisted through a movement.

It is quite unnecessary to have movable 
parallel bars. The ordinary Aldershot standard pattern serves every purpose.

Case 1.-A man sustained a compound fracture of the right radius on October 22nd, 1916, resulting in a stiff wrist. He had been treated by massage, radiant heat, electricity, and pulley machines for seven months with no appreciable improvement. He was just able to put his right hand round the rope, but had no power to support himself owing to absence of grip. The hand could not be supinated beyond the midway position; pronation was full. Treatment was commenced with the hand bag and nautical wheel and his fingers held round the rope by the instructor, while the man performed the movements described under Position 2 (Fig. 10) of the rope. In six weeks he was able to climb half-way up the rope. When treatment commenced, he could not bear his weight on the parallel bars, but a fortnight after trying to climb the rope he could support himself and swing on the parallel bars. The 


\section{JOINT AND MUSCLE DISABILITIES 99}

supination of the forearm was irremediable, though a good compensation for ordinary purposes was obtained by shoulder rotation.

Case 2.- A man sustained a compound comminuted fracture of the left ulna on August 5th, 1917. The arm was in splints for three months, till his admission here on November 7th, 1917. The elbow joint was flexed at a right angle, the fingers were held extended, there was no power of voluntary movement of forearm or hand, the upper arm could be abducted to the level of the shoulder, there were trophic changes of the skin of the hand and fingers. Treatment was commenced on the nautical wheel by acting on the principle so often emphasised by getting the man to do something of which he was capable with his sound limbs and that part of his disabled limb which retained any functions. He was able to advance his disabled arm to the level of the shoulder; accordingly he was set such an exercise on the whecl 
and he received assistance from the instructor. After being for three days at the nautical wheel he was given the hand bag, which he was able to handle by this time. Within a week of admission he was able to hang on a rope, and a month after admission he had a good grip, could freely extend the elbow joint, and could climb a rope and do all ordinary exercises, on all apparatus.

Case 3.-This man is shown at the rear end of the left-hand parallel bars (Fig. 13). He was wounded in August 1917. A metal fragment was removed from the head of the left humerus at the casualty clearing station; some loose pieces of the scapula were removed; the acromion process was found to be fractured. The shoulder joint was treated with "Bip" and the capsule of the joint closed. Three days later a General Hospital note says : "Has large septic wound with purulent discharge from point of shoulder in front and down the back over spine of scapula. Shoulder put up on abduction splint." $\mathrm{He}$ was 


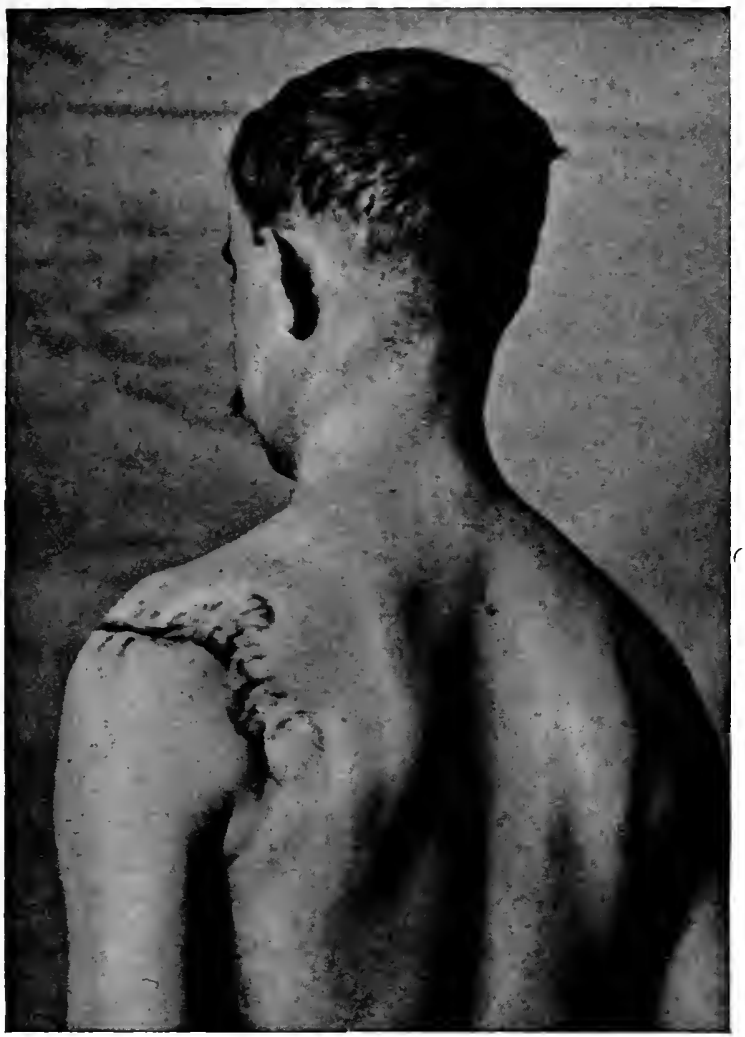

Fig. 14.-Severe Wound of Left Shoulder, with Complete Imorobity of Arm before Treatment. 
sent here in November 1917, when there was a large, irregular scar over the posterior aspect of the left scapula extending forwards over the shoulder joint to a point just in front of the head of the humerus. A drainage tube was in a sinus leading down to the scapula in the lower end of the wound. The arm could be passively abducted to a right angle, but no active movements were possible at the shoulder or elbow joints. The fingers could be flexed into the palm. A radiogram showed that the fracture of the acromion had united, and that the head of the humerus had been perforated.

In a week the sinus had healed, and treatment was commenced by massage and gymnastic exercises simultaneously on the nautical wheel and vertical wrist rollers. Improvement was rapid, and was helped greatly by the man's keenness on getting better. He took a great interest in the exereises set him. In five or six weeks he could begin to abduct the arm, 


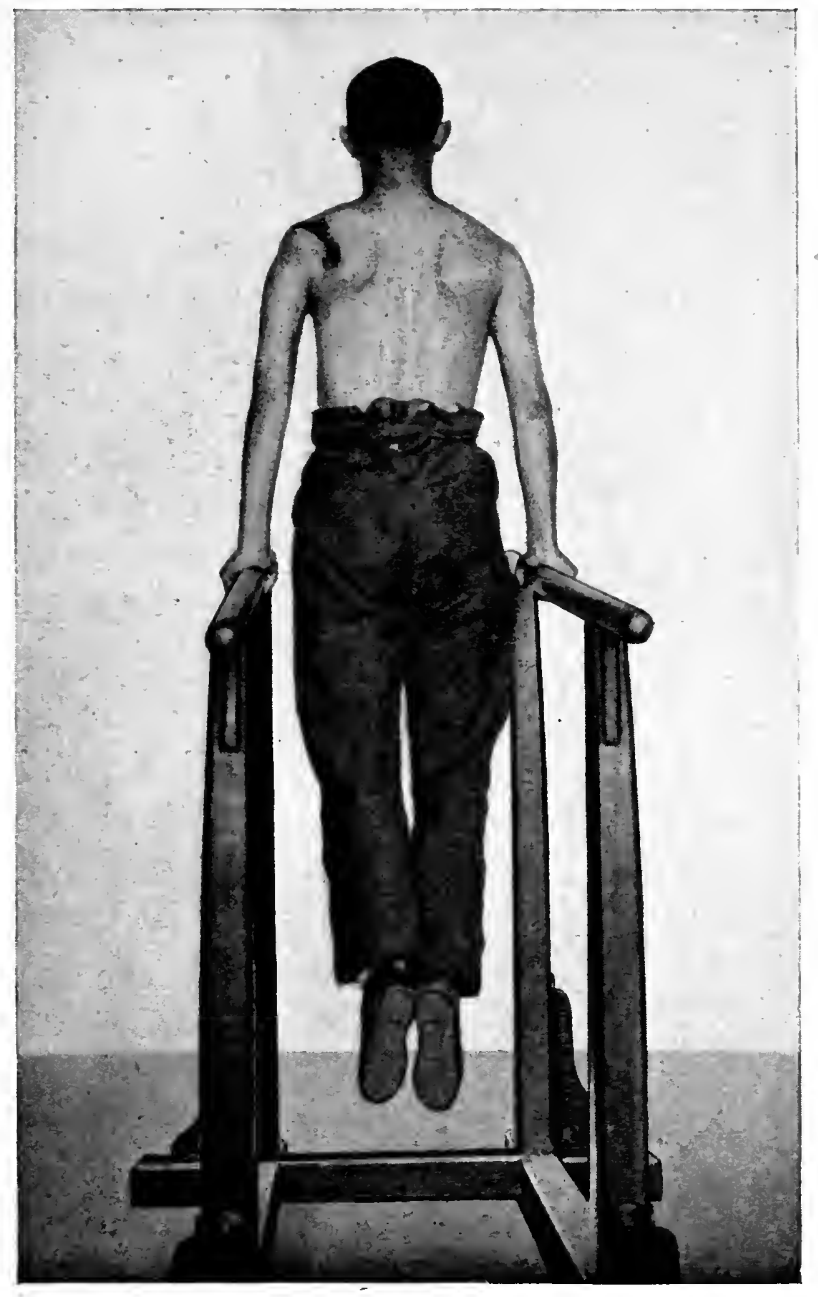

Fig. 15.-Position attained by Patient after Three Months' Treatment. 
and was then given gentle swinging exercises with the Indian clubs; he was next set exercises on the sparred plank, and three months after admission could support himself on the parallel bars, do a short single-arm march, and some of the vaults. He is unable to fully extend his arm above his head, and it is doubtful if he ever will; but except for this there is no limitation of the movements of the shoulder joint. This man's favourable condition is doubtless due to a great extent to the fact that his arm was early put up in an abducted position. This man is also shown hanging on the beam, and appended are separate photographs showing the scar condition.

Case 4.-The man shown at the rear end of the right-hand bars (Fig. 13) was wounded in the right forearm in July 1917, from which shrapnel was removed. In September a note says: "Cannot extend elbow beyond 120 degrees nor flex it beyond a right angle; pronation present, supination lost." He had massage and 
passive movements for two months, and then transferred hcre. There was no power of supination, extension of the elbow was to an angle of 120 degrees and flexion to about a right angle. The power of grip was so weak that he could not hang on a rope, the hand slipping down. Treatment was commenced with the hand bag and light dumb-bells, and in three weeks he could hang on the rope, and could climb after another two weeks, when power of supination had commenced to return. Progress was then rapid ; full flexion of elbow was obtained and extension just short of full, which is no disability; but he still complained of some weakness of supinating power and pain when carried beyond a certain point. I then found that he was an expert signaller, and as the movements of flag signalling are those of alternate pronation and supination, I put him on to going through the Morse alphabet, which he could not do at first, but in three or four days he could do so comfortably and 
at an increasing rate. Had I known that he was a signaller I should have made it a means of treatment sooner.

When means of treatment are limited, and any one with a knowledge of signalling can be obtained, this practice is of great value in treating disabilities of the upper limbs; and the patients in the hospital other than those suffering from upper limb disabilities might well be instructed with the disabled, and so be provided with an entertaining and useful occupation.

If a few medical officers would make it their business to learn it-and every large military hospital is almost certain to have a signaller at some time or other among the patients - they would find many useful applications to be made of the practice. In the early days of the war I made it a point to instruct my medical officers in signalling.

It is unnecessary to multiply the details of the other men in the photograph. They are all instances of various disabilities, which prevented them from 


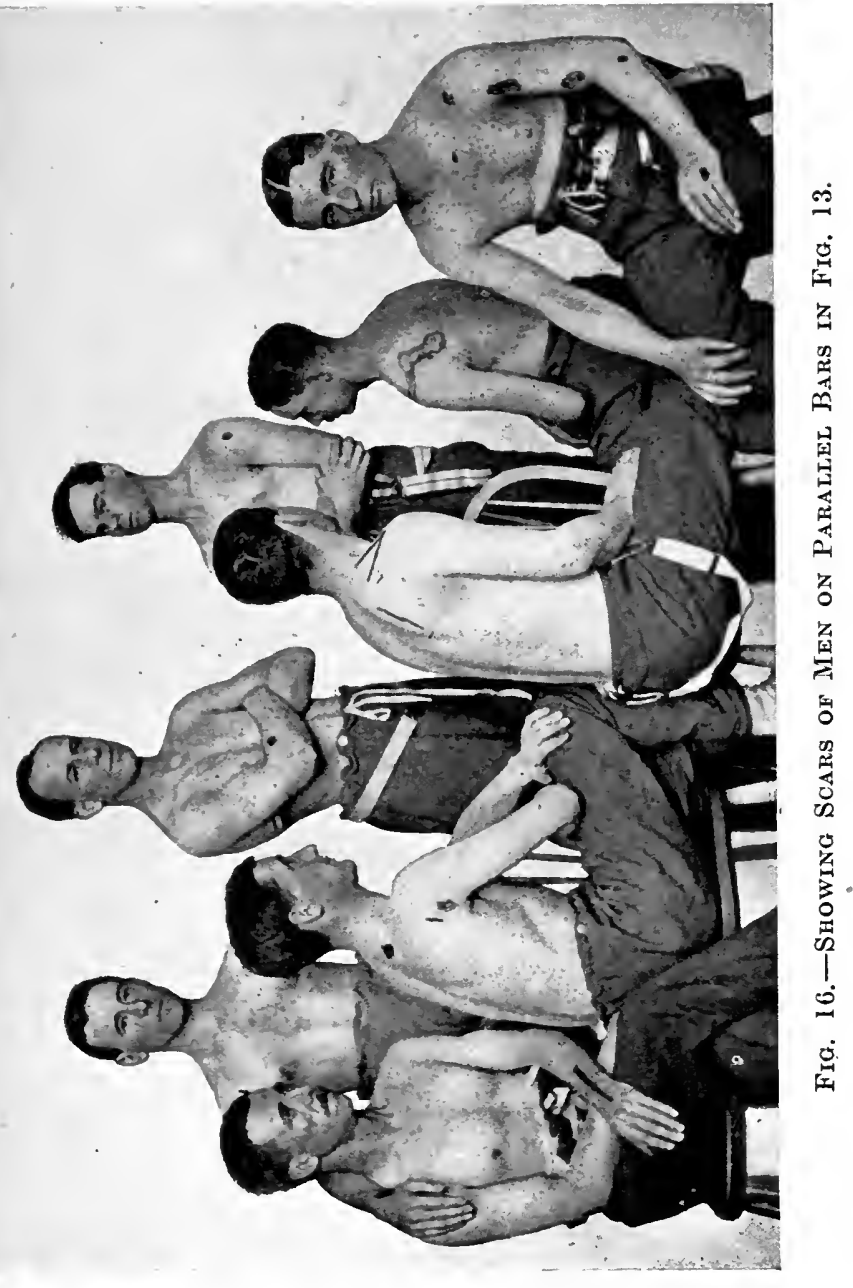




\section{GYMNASTIC TREATMENT FOR}

supporting themselves on the bars without assistance three or four weeks before the photographs were taken. These cases have not been specially selected for my present purposes, but are examples of the average class of case dealt with here daily.

Photographs of the scars of the men shown on the bars are appended (Fig. 16).

\section{The Sparred Plank}

It is worth while referring to this apparatus owing to its wide application to a variety of disabilities, e.g. stiff shoulders, elbows, hips, knees, deficient grip, contracted scars, and weakened muscles.

Here again both sides of the body are being used, and the exercises can be adapted to the weakest limb, whilst the sound ones are being usefully exercised at the same time.

To take one or two disabilities out of many which seem to present considerable difficulty in treatment judging from the 
cases seen here. A patient is unable to raise his arm fully above his head. Experience here has proved that the quickest and most efficacious way in which to aid recovery of extension of the shoulder is to utilise the body weight for the purpose. This point is referred to in the section on the Vertical Rope, and the same application can be made on the sparred plank with this advantage, that it can be utilised with the man lying prone or with his back to the plank. A man who cannot grasp a spar above the height of the shoulder with his back to the plank can often do so when lying prone on the plank. In either case assistance is obtained by the fact that a good deal of the body weight is taken by the plank. Further, weight can be taken off the shoulder by placing one or both feet on the spars. Monotony of movement is obviated by the variety of movements necessary in moving up and down the plank.

This apparatus can be most usefully 


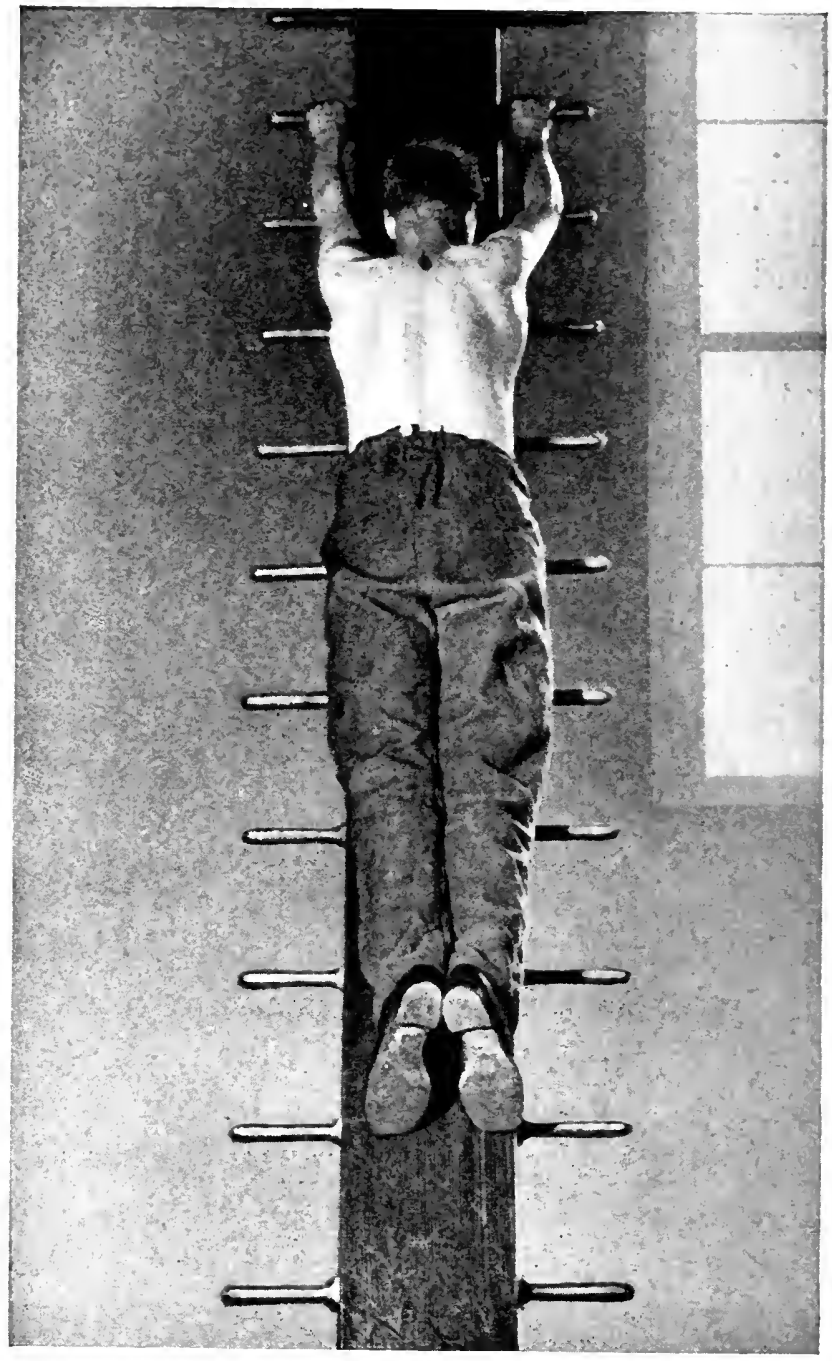

Fig. 17.-Use of Sparred Plank in Arm Disabilities. 


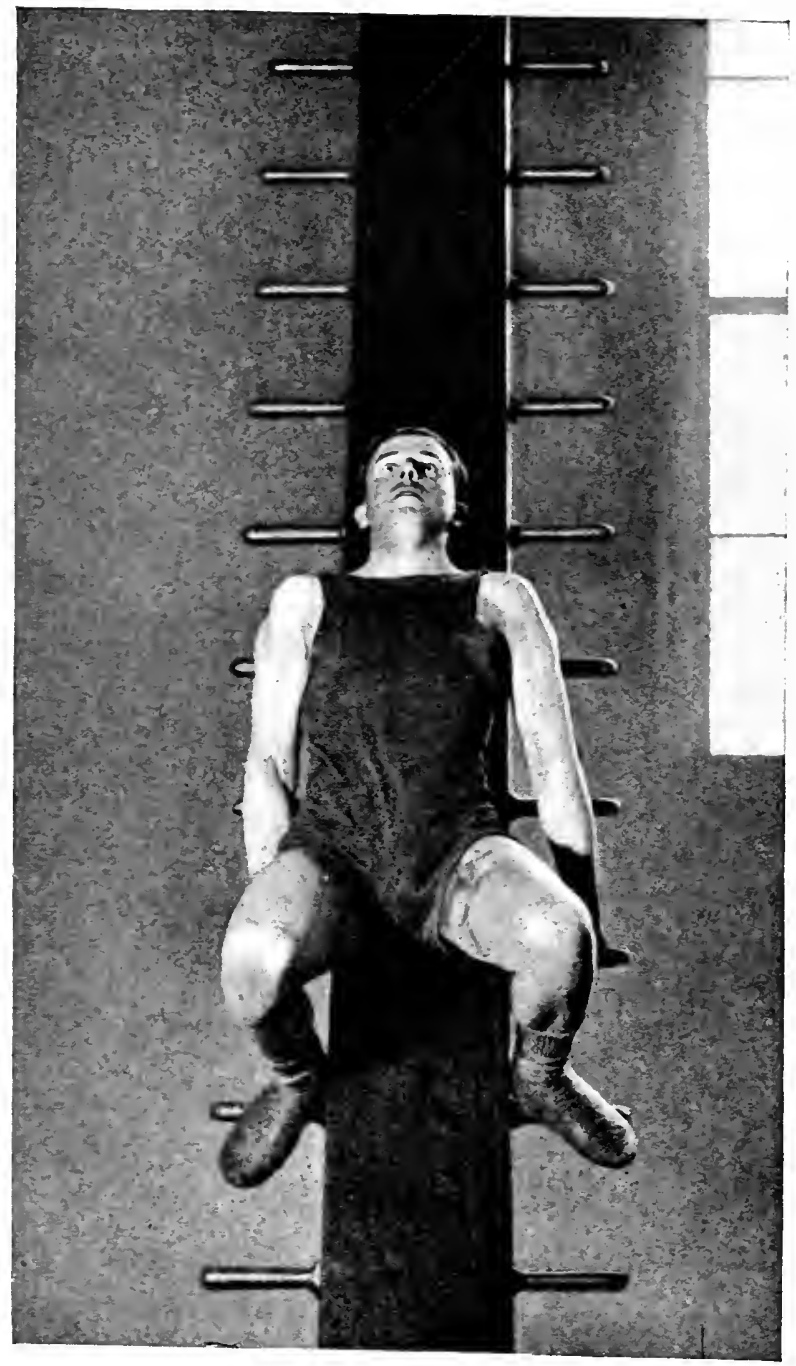

Fig. 18.- - Use of Sparred Plank in Leg Disabilities. 


\section{GYMNASTIC TREATMENT FOR}

applied to stiff knees. Here it affords that alternate flexion and extension which is so important and brings into action all the large flexor and extensor groups of the hip and knee joints, while assistance is obtained from the arms.

Fig. $\mathbf{1 7}$ is of a man who was wounded by an aeroplane bomb on September 22nd, 1917, just posterior to the right sterno-mastoid muscle at the junction of the middle and lower third. The piece of metal, three-quarters of an inch square, was removed at the casualty clearing station from a point to the right of the sixth cervical spine; the transverse processes of the fourth and fifth cervical vertebræ were fractured, and the cervical plexus injured.

On arrival in England on October 5th there was complete paralysis of the right arm. He had massage till sent here on December 28th, during which time there was a gradual return of sensation followed by active movements of the fingers.

On admission here he could abduct the. 
arm to a right angle, flex the elbow and grasp objects, but could not süstain any muscular action. Treatment was commenced on the nautical wheel and wall bars, followed in two weeks' time by the sparred plank and hanging on the rope; and in a month from admission could climb half-way up the rope and could support himself on the parallel bars and perform simple vaults. This man's rapid progress is due to the early commencement of the treatment.

Fig. 18 is of a man who was wounded by a bomb in July 1917, sustaining an extensive wound on inner side of left thigh.

The casualty clearing station note says: "Wounds in left thigh are in extremely bad condition; very offensive; adductor longus dead and was cut away, also the dead connective tissue." He had massage daily for three months before coming here. On admission in January 1918, he was unable to walk without the aid of a stick; the left knee was partially 
flexed owing to contraction of scar tissue over the adductor group. The scar was twelve inches long, dense, irregular, puckered, and adherent to underlying muscle and fascia.

He was put to flexing and extending the knee joints, and on exercises on the parallel bars, on dropping from which he had to be greatly assisted at first. He also played the games described elsewhere. In less than a month he could fully extend the left knee, flex it to an angle of 70 degrees, could balance-walk on the beam, and walk without a limp.

This man is also photographed standing on the beam (Fig. 19).

A knowledge of the use of this apparatus will enable the instructor to dispense with the expensive rowing-machines which are advocated by some. Our object is not to teach a disabled man to row, but to enable him to recover the use of his body and limbs to fit him for his military duties, or failing that end, to render his injury less disabling for civil employment. 
JOINT AND MUSCLE DISABILITIES 115

\section{The Beam}

The beam referred to is that known as the Swedish Beam. It is of more general applicability to our purposes than the ordinary gymnastic beam. It can be used at various heights and has a flat surface which can be placed uppermost.

It is impossible to describe the multiplicity of exercises which can be applied to different disabilities of the trunk and limbs. Special note may be made, however, of the use of this apparatus to a requirement of frequent occurrence, namely that of re-educating a man to walk. It affords the quickest means of showing a man who has developed into a confirmed crutch-walker that he can get rid of his crutches and sticks.

Any man who is able to stand can be put to balance-walking on the beam, which brings into co-ordinate action all the large groups of back and leg muscles.

A case that was in hospital recently was that of a man who had acquired the 


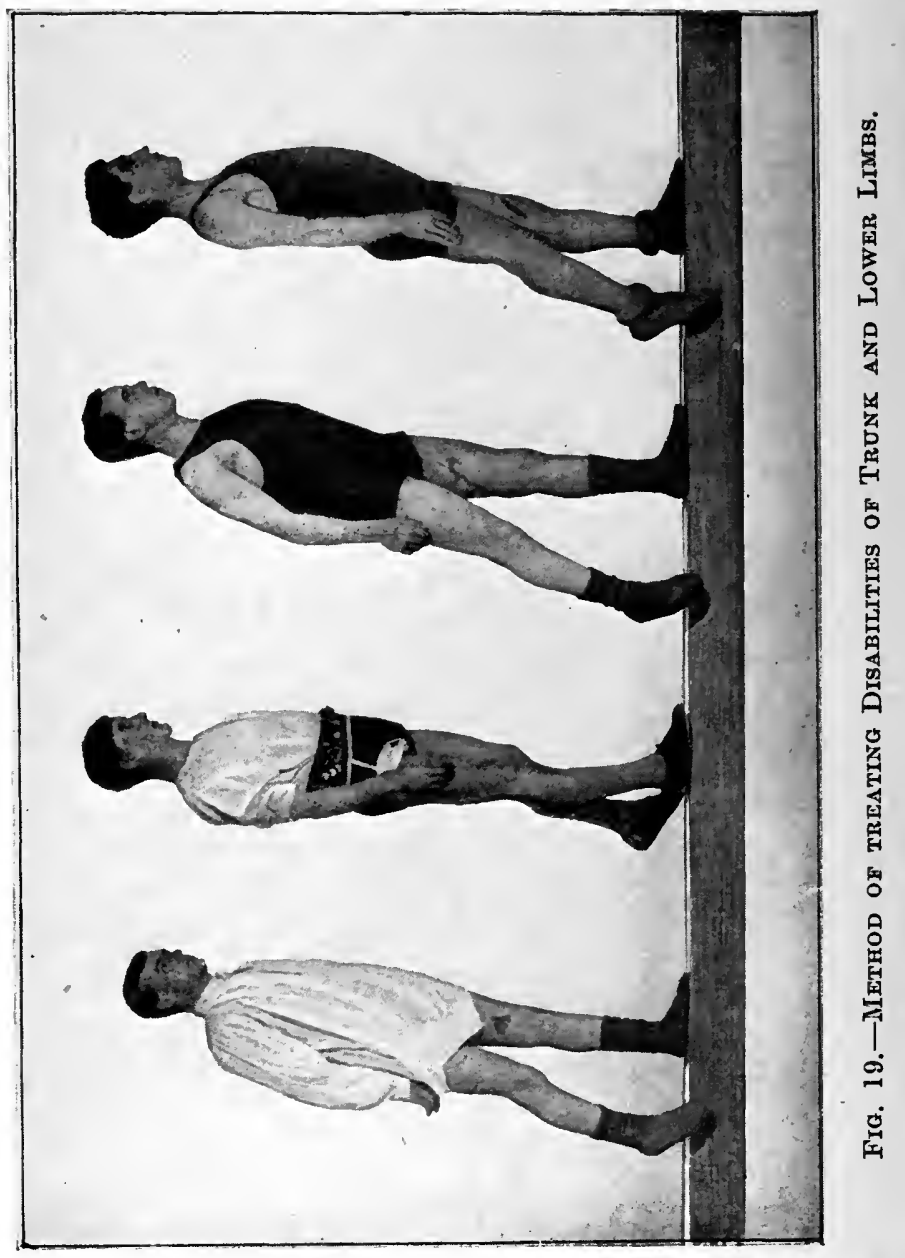




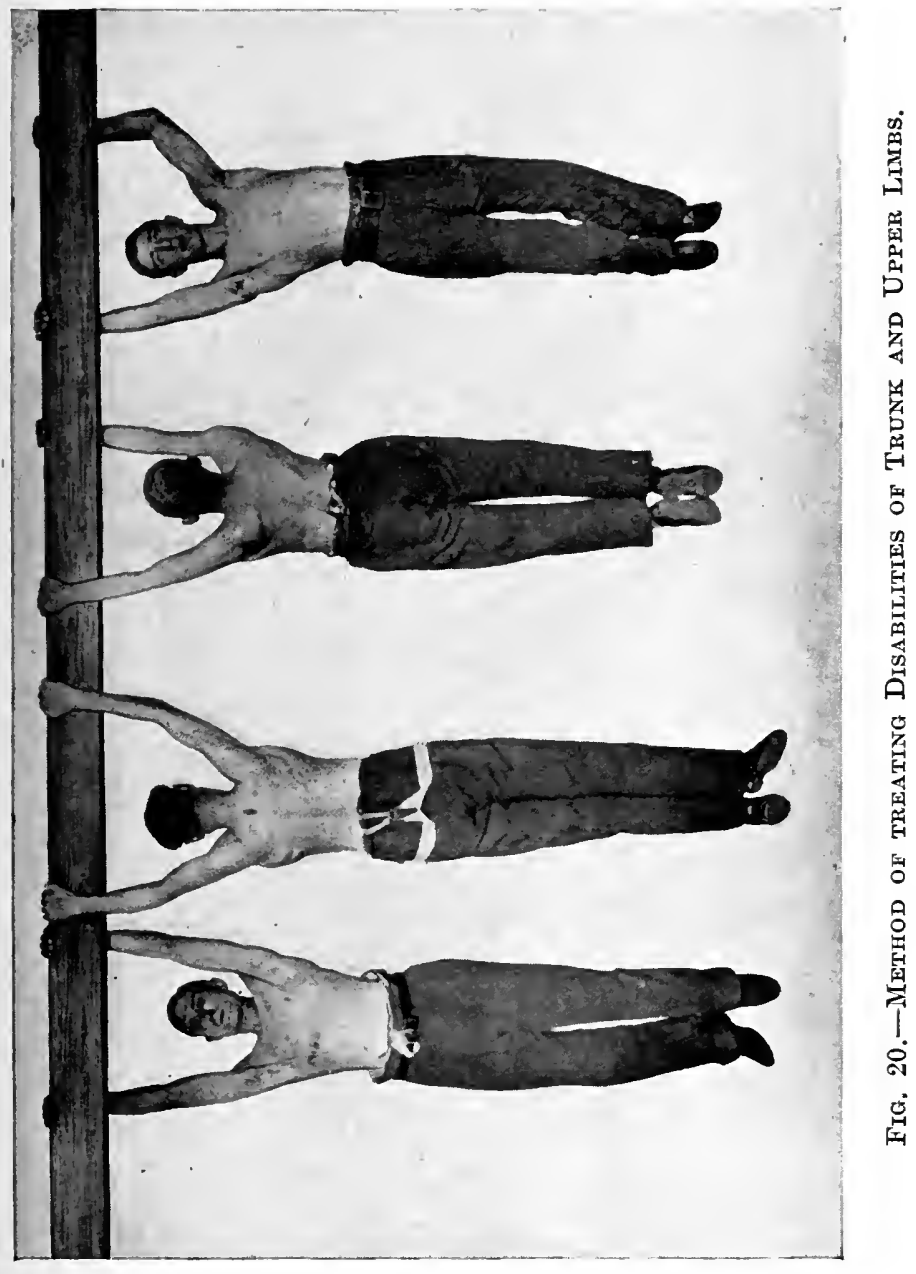




\section{GYMNASTIC TREATMENT FOR}

fixed habit of walking lame with one leg spread out and the foot everted. It may seem an exaggeration, but this man after a few minutes' training was able to walk unaided on the beam, and then walked quite straight on the ground.

At first the man can be assisted to any required extent. Assistance is often necessary merely to give him confidence apart from any physical disability.

Figs. 19 and 20 show how the beam affords a variation of exercise for special treatment of stiff joints, scar contractures, and weakened muscles. The man can swing the sound leg backwards and forwards and from side to side. If necessary these exercises can be done with assistance.

An ideal method of re-educating the walking power is the practice of the old "Goose-step," which I learnt in 1882 on the Aldershot Parade Ground. This exercise will be found described in the Infantry Drill Book of that period. Like every other form of exercise, it is better learnt 
from one who knows it. It is no longer part of the parade-ground drill, but it is a valuable relic to apply to disabled men.

Balance-walking can be usefully applied to some cases of disability subsequent to trench-foot, in which inversion is common. The foot is held down as flat as is possible by the instructor while the man puts his weight on to that foot and places the other in front.

\section{Leg Exercises}

Though it is impossible to deal in detail with the many and varied conditions of the joints of the lower limbs with the methods of applying means of restoration of function, some practical points connected therewith which have a special bearing on the treatment of affections of the knee-joint may be usefully mentioned.

I make no attempt to deal with the subject of diagnosis of knee-joint affections, as medical literature teems with the subject. 


\section{GYMNASTIC TREATMENT FOR}

I propose to deal only with that aspect of a case in which movement has been decided on as being advisable. Take the very common case of a knee which has suffered from one or other form of internal derangement, and in which all inflammatory action is at an end. Here, in all probability, the thigh muscles are wasted and the patient finds that his knee "gives" under him, especially during such a movement as going upstairs. In an extreme case of the kind it will be found that the patient cannot tighten up the quadriceps extensor group, or that the muscular contraction is appreciably delayed as compared with the sound side. Here the patient should practise tightening up each thigh alternately so as to move the patella. This with other movements to follow can be done at intervals throughout the day, no matter where the patient is or what he is doing, and so can be rendered independent of any set treatment. The same exercise should be practised with the leg raised to different heights according 
to capacity, both with the foot free and supported on a chair or table. This brings me to an important point.

It is a common practice with the users of pulley machines to give repeated movements on the pulleys with the affected leg only. The greater effect of such movements is confined to the leg on which the patient is standing, and which requires no specific treatment. This can be seen, felt, and realised to be the case. Watch a patient stripped, and feel the two limbs while in action, or better still do it yourself, and it will be obvious that the extensor muscles of the thigh are in considerably greater action on the standing leg. A simple way of demonstrating this is to stand on one leg and raise the other thigh to the level of the hip with the leg hanging from the knee. There will be no consciousness of effort with the raised leg. Then extend the leg on the raised thigh so as to straighten the knee. The chief difficulty will then be found to maintain the posture on the standing leg in which the 


\section{GYMNASTIC TREATMENT FOR}

hip and thigh muscles are brought strongly into action not only to maintain the balance, but to prevent the knee bending. If any one will try it, he will appreciate the difficulty of keeping the knee of the standing leg properly extended.

The muscular support of the body on the knees depends on the quadriceps extensor and tensor fasciæ muscles, and to set a man who requires to regain that support to do adductor exercises on pulleys with the affected limb is waste of time and is demoralising to the man.

As soon as it is decided that the man may safely stand on his affected leg, he can take off weight by holding on to some object. In many cases the inability to stand on the affected leg is simply due to want of confidence, and when he tries the muscles shake. The next simple movement is for him to stand on the affected leg, either with or without the assistance of holding on to something, and then to kick with the sound leg and the affected one alternately. This kicking 
exercise is practised here by the whole class, who stand round in a circle with their arms on each other's shoulders. To increase the action of the kicking, it can be done at any angle. For instance, the right leg can be carried sideways to the left or right as well as to the front. During these exereises both knees should be kept as straight as possible.

This means of exercising the legs is referred to in the section on the "Beam" (Fig. 19).

It should be noted that the men are balancing on one leg, the other foot not touching the beam.

The next most simple exercise for the thigh muscles and knee joints is for two men to sit on the floor back to back, with the feet drawn up well under them as far as is comfortably possible. As they press against each other's backs, they rise to the standing position, and still retaining their backs in contact they can resume the sitting position and repeat. The positions are shown in Figs. 21 and 22. 
124 GYMNASTIC TREATMENT FOR

In cases where the men have a difficulty in raising themselves, they can assist themselves by pressure on the floor with the hands, or by linking their arms. This exercise can be done in class-work. A disabled man can be put to do this

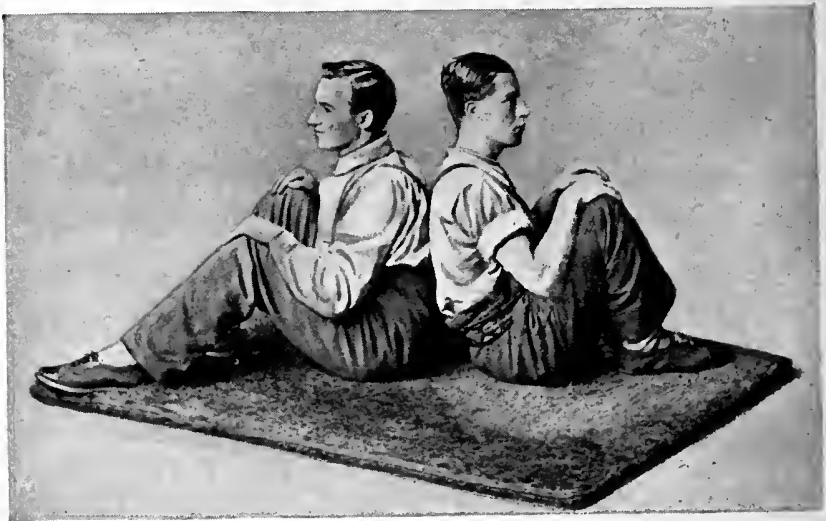

Fig. 21.-Exercise for Thigh Muscles and Knee Joints.

exercise when one limb is disabled and it provides good exercise for the sound limb as well. It is often advisable to set the exercise for a man with a disabled leg with a man not so disabled.

Space does not admit of describing all 
JOINT AND MUSCLE DISABILITIES 125 the ordinary knee-bending exercises with and without apparatus which form part

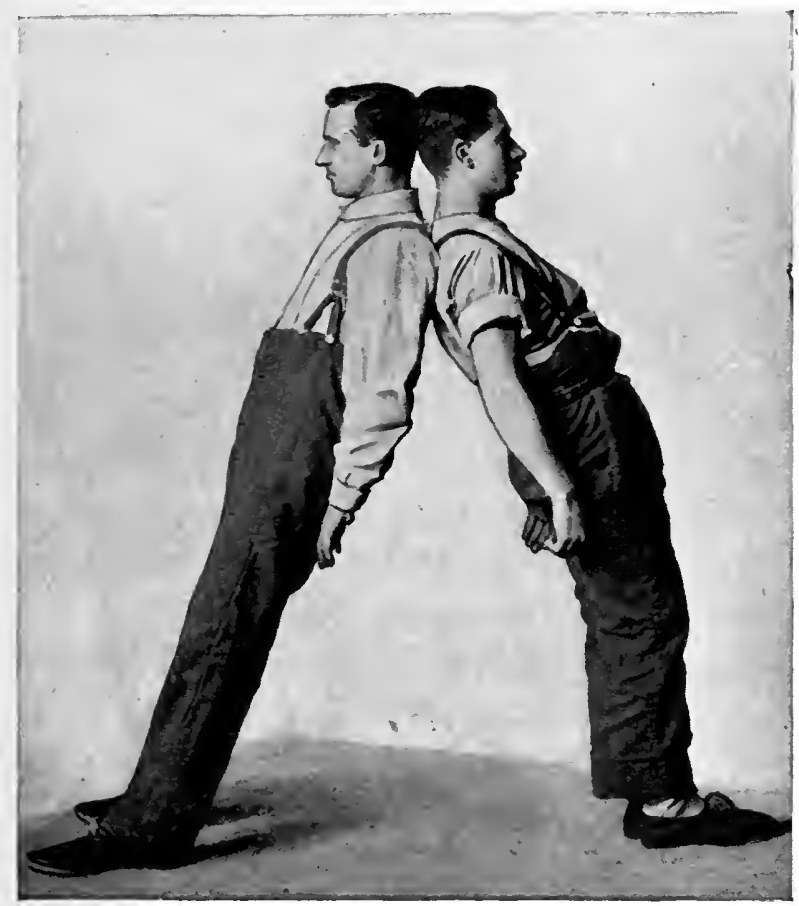

Fig. 22.-Second Position.

of the routine class-work here, but it may be noted that in cases where the thigh muscles are very weak, the man's 
voluntary efforts can be assisted by his partially supporting himself by his hands. An illustration of this may be given. A man bends his knees to an extent which will enable him to place his hands on two chairs placed on either side of him. He then straightens out one leg to the front, putting his heel on the ground. He then lets as much weight as possible bear on the other leg. Then he draws the extended leg under him again and extends the other leg. As strength is acquired, he extends one leg at the same time as he draws the other under him. The same thing is done later on without the aid of the chairs, by taking support with the hands on the floor. The exercise when performed on the ground constitutes the " frog-step," which is a marked feature of Russian dancers, and though disabled men need not be retained under treatment till they can perform it in its entirety, it is a good instance of how such an exercise can be adapted to the needs of disabled men. 
It may be noted that if the exercise is done without the aid of the hands, the arms should be extended at first in front of the body, which is also bent a little forward so as to maintain a balance. To perform it with the arms folded and the body more upright requires more power of balance than a disabled man may be expected to attempt.

For spccial leg treatment there are many exercises which for cultivation of power and co-ordination are vastly superior to the free movements usually described in some books and are more enlivening for the men. For instance, take the "footsideways-place" movements. In these movements there is no "life." If a man can do these exercises he can do other exercises with greater benefit. A modification of the "foot-sideways-place" is practised here in the class, but does not admit of adequate written description. In practice it brings into action the legs, arms, and body. I learnt this exercise a few years ago from a professional acrobat; 


\section{GYMNASTIC TREATMENT FOR}

and it is another instance of how movements suitable for exhibition by a highly trained man can be adapted to the treatment of disabilities.

Another exercise which is done in class here has an application not only to disablement of thigh and hip muscles, but also the knee joints and upper limbs.

The men stand in a ring, one behind the other. Each man places one hand on the corresponding shoulder of the man in front of him; raises his opposite leg backwards, so that the man behind can catch hold of the instep: The men all hop on their own ground, or go forwards or backwards.

Men who are rather more advanced can be placed in a ring by themselves, and when in the above position, bend and stretch the standing leg.

A variation can be made by raising the leg forwards, which is grasped by the man in front.

The wheel-barrow which is made use of here is also a useful exercise, especially 
JOINT AND MUSCLE DISABILITIES 129

for disabilities of the upper limbs, and applies to both men engaged in it.

A useful variation of lower limb exercise for class work is jumping off one foot as the other foot is raised sideways, and kicking the heels together before landing. The exercises, like all others, should be demonstrated by the instructor, and even if it is probable the patients cannot kick their heels together, nevertheless their disabilities are being efficiently treated by the voluntary effort to jump up, and that is the end in view.

Use is also made of a hornpipe step and of some of the step-dancing movements. It is encouraging to all concerned to see how a class will take to them, and it is also interesting to watch what a disabled man can do. These exercises can be learnt by any one who wishes to apply them, and age cannot be advanced as a valid reason for not so doing. They can be seen in operation at this hospital, and I would gladly teach any one who wishes to learn them. 
Referring to the photographs, the lefthand man had a wound of the left thigh on April 1st, 1917. The wounds had healed at the end of four months, by which time the knee had become stiff. He was sent here by Colonel A. Carless for treatment by gymnastic exercises. He was admitted on September 5th, 1917. There was a large, irregular, depressed, and adherent scar covering one-third of the inner surface of the left thigh, also a long linear operation scar and two smaller linear wound scars on the back of the thigh. The knee joint admitted of active flexion up to an angle of $130^{\circ}$ only, owing to the adherence of scar tissue to the muscles. The scars were very tender, extension was not quite full. He was set to walking up and down the slanting ladder and to perform the exercise as shown in the photograph. On November $\cdot 5$ th, 1917, he could flex the knee to an angle of $100^{\circ}$, and had full extension. By December 12th, 1917, he could flex the knee to $85^{\circ}$. The scars 
gradually became less tender, but the fact that the scars were tender did not militate against his being placed on such voluntary excrcises.

\section{The Wall Bars}

These are the least essential part of the outfit of the gymnasium, but they provide alternative means of performing certain exercises, and are useful where a large number of men are treated. Three sections are sufficient for a gymnasium in which five hundred men are treated. They are useful for providing means for aiding recovery of flexion and extension of the knee joint, and the bars being close together enables one foot to be placed between two bars at any desired height, and the toes fixed under the upper one, thus providing a purchase, while the man stands on the other leg. In utilising this apparatus for extension of the knee, I wish to emphasise the point on which $I$ lay stress in the sections on "Leg Exercises" and the "Pulley Machines." 
Do not confine the treatment to having the affected leg put up on the bars, but have the sound one also put up while the man stands on the affected leg. The best way to appreciate the value of this is to stand sideways to the bars, raise one leg to about the height of the hip on the bars, maintain the body at right angles to the bars, and straighten both knees. The probability, indeed from experience I might almost say certainty, is that both knees will not be extended, and that the body will not be maintained upright, but be flexed at the hips and turned towards the bars. If now one knee be extended, the other will be flexed. Get some one to prevent knee flexion of the raised leg, and then try to stretch the body up, when it will be found that it has a tendency to extend the knee of the standing leg. The effect of this movement is increased by having the foot of the standing leg turned out, though at first this will be found difficult. These bars are inferior, generally speak- 


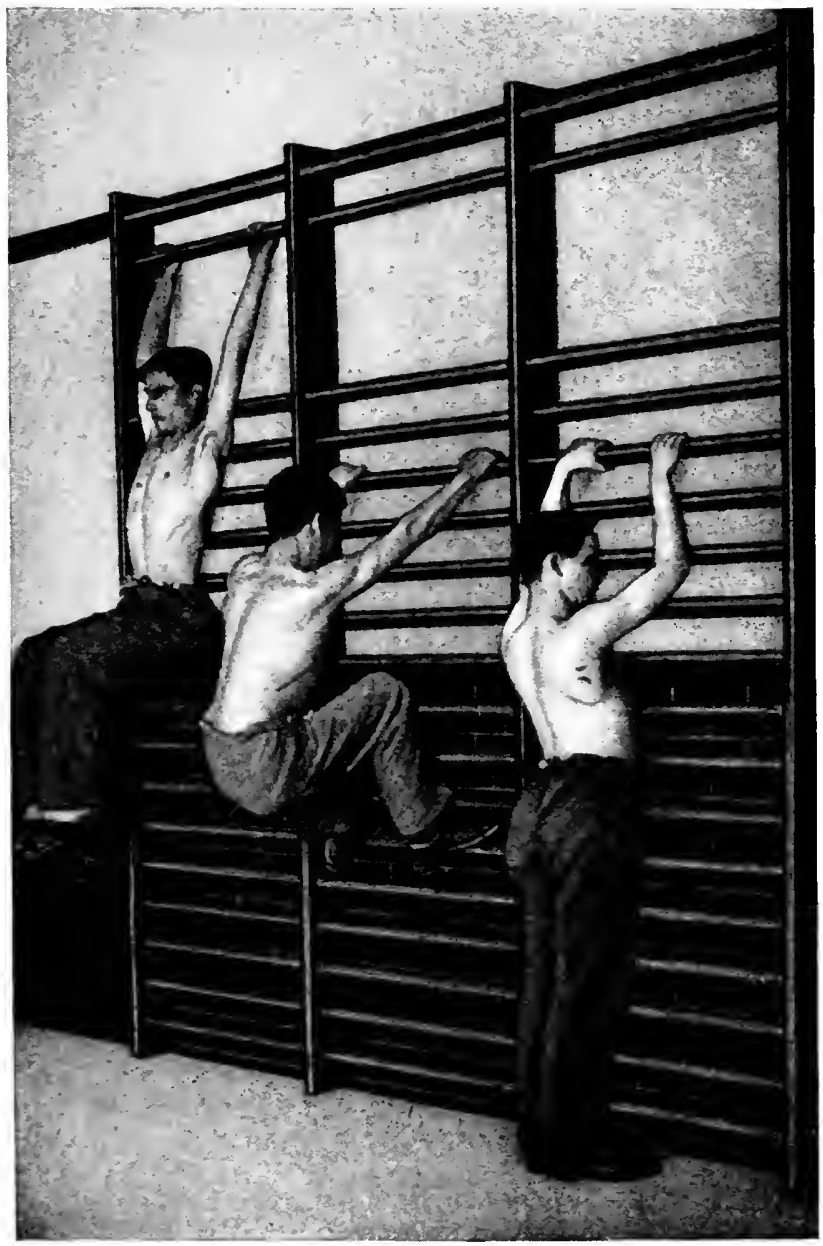

Fig. 23. - Method of applying Wall Bars to Ĺpper and Lower Limb Disabilities. 
ing, to the ladder, sparred plank, and other climbing apparatus, inasmuch as they do not allow of travelling movements.

\section{'The Nautical Wheel}

This apparatus can be usefully applied to deficient movements of all the joints of the upper extremity, especially extension of the shoulder, flexion of the elbow, and fingers, pronation, and supination.

The man shown in the photograph has bony ankylosis of his right elbow-joint and defective power of grasp, which is improving by the use of this apparatus. The loss of power of flexion of the elbow does not militate against his using the wheel, as when he wants to turn it round with the affected arm he lays the body back and pulls from the shoulder. When used for pronation and supination, the man should stand in the proper steering position, at one side of the wheel and facing it. If the right arm be affected, 


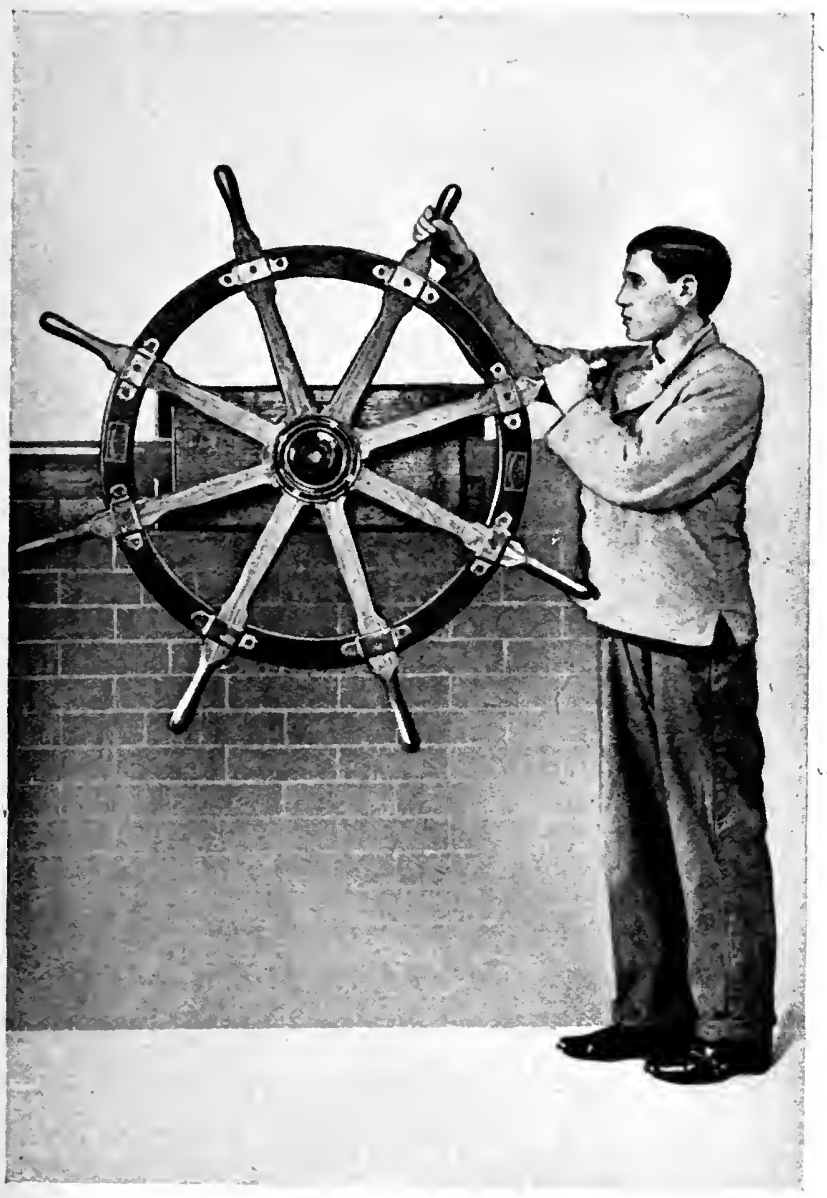

Fig. 24.-Use of NaUtical Wheel for Disabilities of UPPER LIMBS. 
he should stand at the right of the wheel and vice versa. The wheel should be turned right and left, thus bringing pronation and supination with both hands into frequent alternate action. This apparatus shares with the Indian clubs the advantage of bringing into co-ordinated and associated action the complete movements of pronation and supination. Resistance to the turning of the wheel is provided, and this can be adjusted to the needs of the patient. This is a convenient plaee to emphasise a point equally applicable to a sound man training in gymnastics and to a disabled man. He should not be kept turning the wheel set at one resistance. When he has performed a few turns at the maximum of which he is capable, resistance should be lessened by degrees down to the minimum, and then again varied. The man can alter the resistance himself by turning the screw. This greatly facilitates and hastens the recovery of power in a disabled man and the development of power in a sound man. 


\section{GaMes}

The kind of games played must be left to the choice of those responsible, and they may vary according as they can be played in the open or in a building.

The value of these consists in the fact that they bring the bodily functions into play that have become damped down by a prolonged stay in hospital, and in addition have the advantage of enabling a man to forget his disability in the excitement of the game. It is interesting to see how Nature will automatically compensate for some deficient movement, and how a man will perform a movement of which he had thought himself, and of which others may have thought him, incapable. For instance, a man who had previously been unable to raise his arm above his head, in the excitement of being chased by another man, jumped to catch hold of a beam with both arms above his head so as to hang with both feet off the ground. 


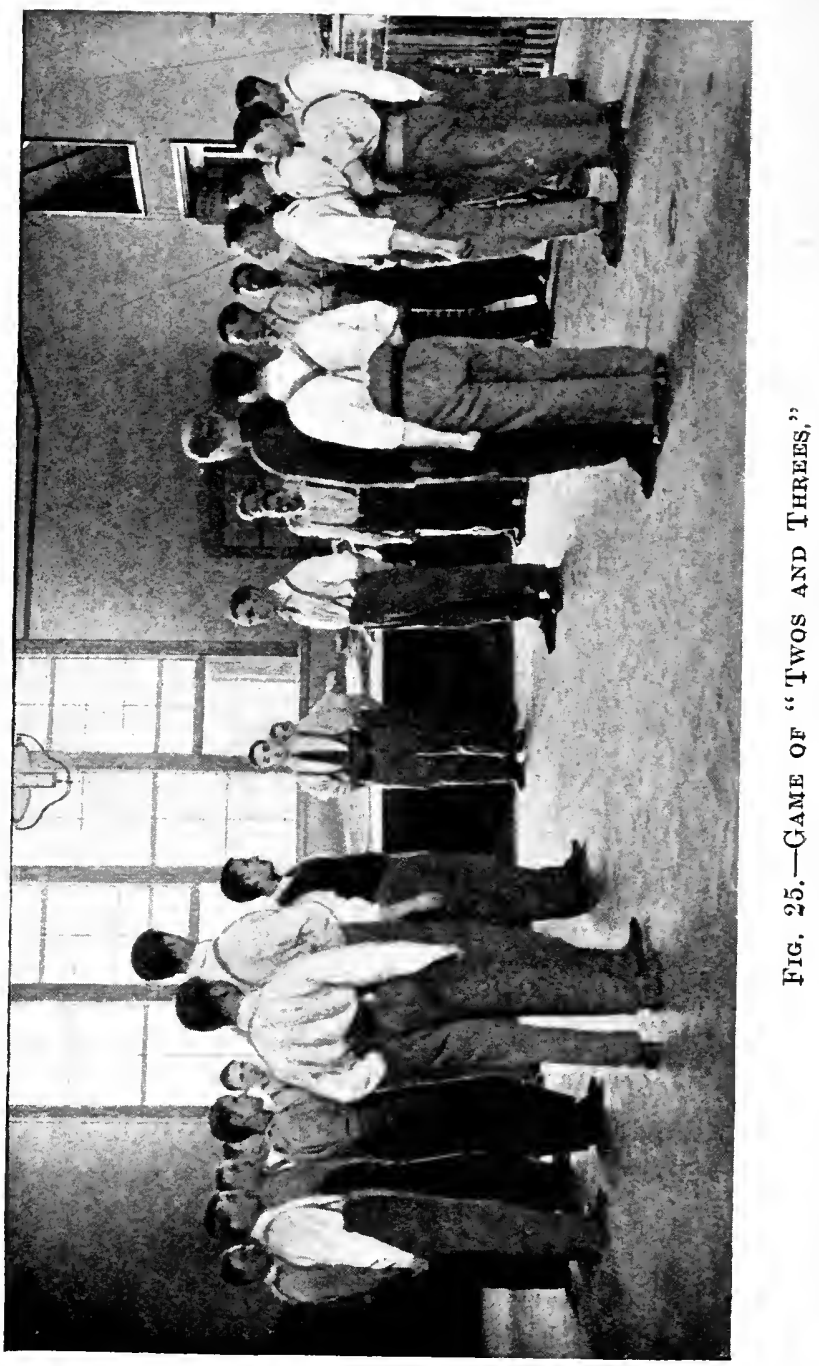




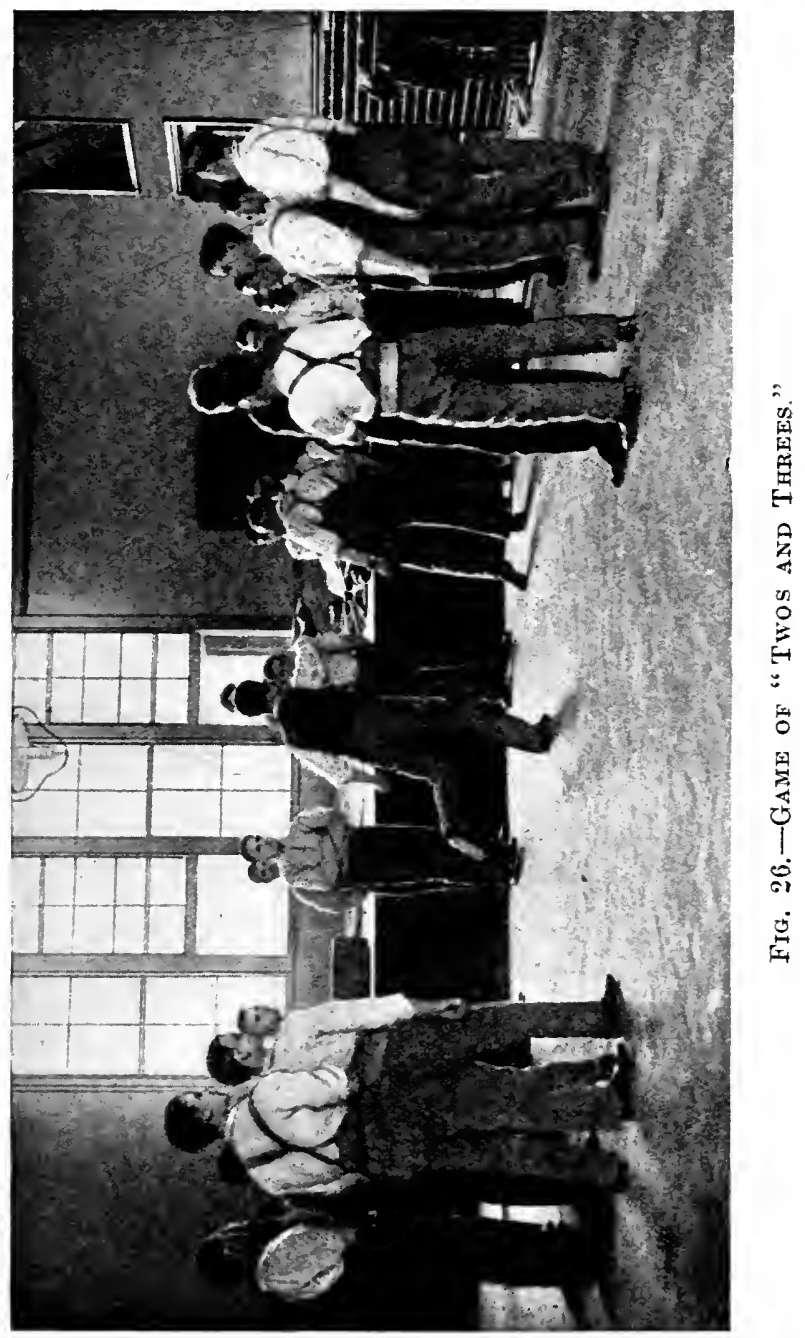




\section{GYMNASTIC TREATMENT FOR}

It may be useful to describe the two games mostly played in the gymnasium here.

"Cat and Dog."--One man plays the part of the dog, and the rest that of cats. The dog tries to catch any cat before the latter can get on to any piece of apparatus so that the feet are off the ground. The cat can get into any position he likes on any apparatus so long as the feet do not touch the ground. If the dog catches a cat before the latter can get his feet off the ground, then they change rôles. It may be necessary sometimes for the instructor to prevent men from getting on to an apparatus and stopping there comfortably; they must all keep on the move.

"Twos and Threes." - The class is arranged in a circle which may be as large as space allows, or as small as desired. The men are placed in couples one behind the other. A man is placed in the centre of the circle ; he is called the "Catcher." Another man is placed anywhere the instructor may determine, provided he is 
at some little distance from the catcher; he is known as the "Third man." The catcher has to touch the third man before the latter can place himself in front of any two of the men forming the circle. When the third man has so placed himself, there are then three men in that section, and as no section must contain three members, the rear man of that section must at once run away, and he must place himself in front of any two men before being touched by the catcher. If a man is touched by the catcher before he can place himself in front of any section, he in turn becomes the catcher. Figs. 24 and 25 will make the game clear.

All the ordinary games, such as skittles, bowls, croquet, etc., can be usefully applied to many disabilities, and where means and opportunity are available, their practice should be carried out as part of the treatment under supervision ; and at other times the games can be played as the men like. 
During the summer a modified hand football is played here, to which the men take keenly, and an onlooker might be surprised to find that the men could not fulfil one of the three postulates qualifying them for the fighting line. 


\section{N D E X}

Abacot handbag, 54

Adhesions,

limitations of movement due to, 19

treatment of, 20

Apparatus,

advantages of, 38,39

kinds required, 41,42

object of the use of, 43

selection of, 53

Appliances, mechanical, 16

Arm,

extension obtained by rope climbing, 84

loss of voluntary movement, exercises for, $86,88,89,101,102$

Arm disabilities,

nautical wheel exercises for, 134-6

signalling exercises useful for, 105

use of sparred plank in, $109,110,112,113$

wall-bar exercises for, 132, 133

Associated movements, importance of, 36,49

Back injury,

case illustrating use of club swinging, 67
Beam exercises,

cases suitable for, 118

method of treating disabilities of trunk and lower limbs by (illustrations), 116, 117

power of walking reeducated by, 115

Bony deformity, 19

Climbing,

see Rope climbing

Club-swinging,

see Indian clubs

Contractures,

psychogenic nature of, 25

successful treatment of, on what dependent, 24

Co-ordination,

club swinging useful for, 59

movements for cultivating power of, 127

Croydon War Hospital, results of treatment at, 17 , 20

Dance steps, 71, 129

Deformities, general observations on treatment, 13

Elbow joint,

bony ankylosis of, exercise for, 134 
Elbow joint (continued) complete fixation, treatment by club swinging, 67-70

re-education of movements of, $52,56,71$

Exercises, condition of muscles for, 48 demonstration of, 45,46 to be alternated, 51 see also Movements

Fingers,

complete fixation, treatment by club swinging, $67-70$

loss of voluntary movement of, case illustrating treatment, 88 , 90

re-education of move-

Flexion, ments of, $53,56,65,71$

movement of, how facilitated, 50

Forearm,

loss of voluntary movement of, parallel bar exercises for, 99

Fractures,

observations on treatment of, 18

Frog-step, 126

Games,

advantages of, 137-42

" cat and dog," 140

"twos and threes," 140 , 141

Goose-step, 118

Grip,

recovery of power of, 53, $54,57,134$

Gymnastic apparatus, types of, 41,42

Gymnastic instructor, qualifications of, 39
Gymnastics,

advantages of, $17,24,25$, 33

class of cases suitable for, 33

definition of the term, 31 , 32

importance of early treatment by, 17, 18, 41, 43

loss of man-power due to non-appreciation of, 89

see also Movements

Hand,

inability to grasp with, 52 , 53

loss of voluntary movement of, exercises for, 86,90

Handbag,

use of, 52-6

(illustration), 54

Hand grasp,

exercise for, 134

re-education of, 57

Heart,

action of, how promoted, 71

Hornpipe step exercise, 129

Hot bath, condition of muscles improved by, 48

Indian clubs, cases illustrating use of, 65,67

difficulties of movements with, 47

elementary movements with, 58, 59-64

pattern suitable (illustration), 57

use of, 53, 56-70

Joints,

alternate movements of, $46,47,49,51,87$ 
Joints (continued)

limitations of massage in treatment of, 15

stiff, beam exercises for, 118

Kicking exercise,

for leg disabilities, 122,123

Knee joint, 20

exercises for, 114, 120-28, 131

-recovery of flexion and extension of, 131

Leg disabilities, exercises for, $119-30$

parallel bars useful for, 95 , 96

use of sparred plank in, $109,111,113$

wall-bar exercises for, 132 , 133

Lungs,

action of, how promoted, 71

Massage, disadvantages of, 90

limitations in its utility, 14,15

Mechanical appliances, restoration of mobility by, 16

Mirror,

Indian club exercises a:sisted by use of, 47

Movements,

associated, 36,49

condition of muscles for, 48

demonstration of, to the

patient, $39,40,45$

general observations on, 45

limitations in, causes of, 19 massage in relation to, 15 mechanical appliances for, I 6

method of performing, 46 , 47
Movements (continued)

not to be concentrated on disabled limb, 46, 87, 132

of sound as well as disabled limbs, importance of, 46, 87, 132

to be alternated, $46,47,49$, 51,87

value of, 18

voluntary, advantages of, 34

Muscles,

condition of, howimproved, 48

club swinging a good training for, 59

weak, beam exercises for, 118

Musculo-spiral paralysis, exercises in cases of, 50

Nautical wheel, cases suitable for, 134

Nerve injuries, limitations of massage in treatment of, 15

Orthopædic treatment, observations on, 13

Parallel bars, advantages of, 91, 92, 94, 95

cases illustrating, 98-104 position of "rest" between 93,94

Paralysis,

functional, psychogenic nature of, 25

successful treatment of, on

Pronation, what dependent, 24

movement of, 55,56

how recovered, 67

nautical wheel exercise for, 134,136 
Pulley exercises, how carried out, 50

Pulley machines, disadvantages of, 73-5, 121

uses of, 72

Radiant heat,

limitations in the use of, 49

Rope climbing, advantages of, $75,76,81$, 84

cases illustrating, 86,89 , 90

cases suitable for, 75

methods of, 78-81

positions for, $77,78,80,81$, 84

(illustrations), 79, 82, 83, 85

Scar contractures,

beam exercises for, 118

Shoulder joint,

complete fixation, treatment by club swinging, 67-70

exercise for extension of, $81,84,109,134$

Indian clubs suitable for stifiness of, 58

re-education of move- ments of, 56,71

Signalling,

useful exercise for arm disabilities, 106

Skipping rope, advantages of the use of, 71,72

Sparred plank,

cases suitable for, 108

(illustrations), 110, 111

Step-dancing movements, 71,129
Supination, movement of, 55,56

how recovered, 67 nautical wheel exercise for, 134,136

Thigh muscles, exercises for, 120-27 wasting of, 120

Trench foot, exercise for disability subsequent to, 119

Vertical rope, see Rope climbing

Volition, mechanism of, 24 necessity of, $15,34,35$ stimulation of, 35

Walking, re-education by beam exercises, 115

Wall bars, method of using, 132, 133 uses of, 131

Wheelbarrow exercise, 128

Wrist drop, case illustrating treatment, 88

Wrist joint, complete fixation, treatment by club swinging, 67 stiff, case illustrating parallel bar exercises, 98

Wrist machines, how to be used, 50

Wrist movements, 55 re-education of, 52,56 skipping rope useful for, 71

Wrist rollers, disadvantages of, 73-5 uses of, 72 




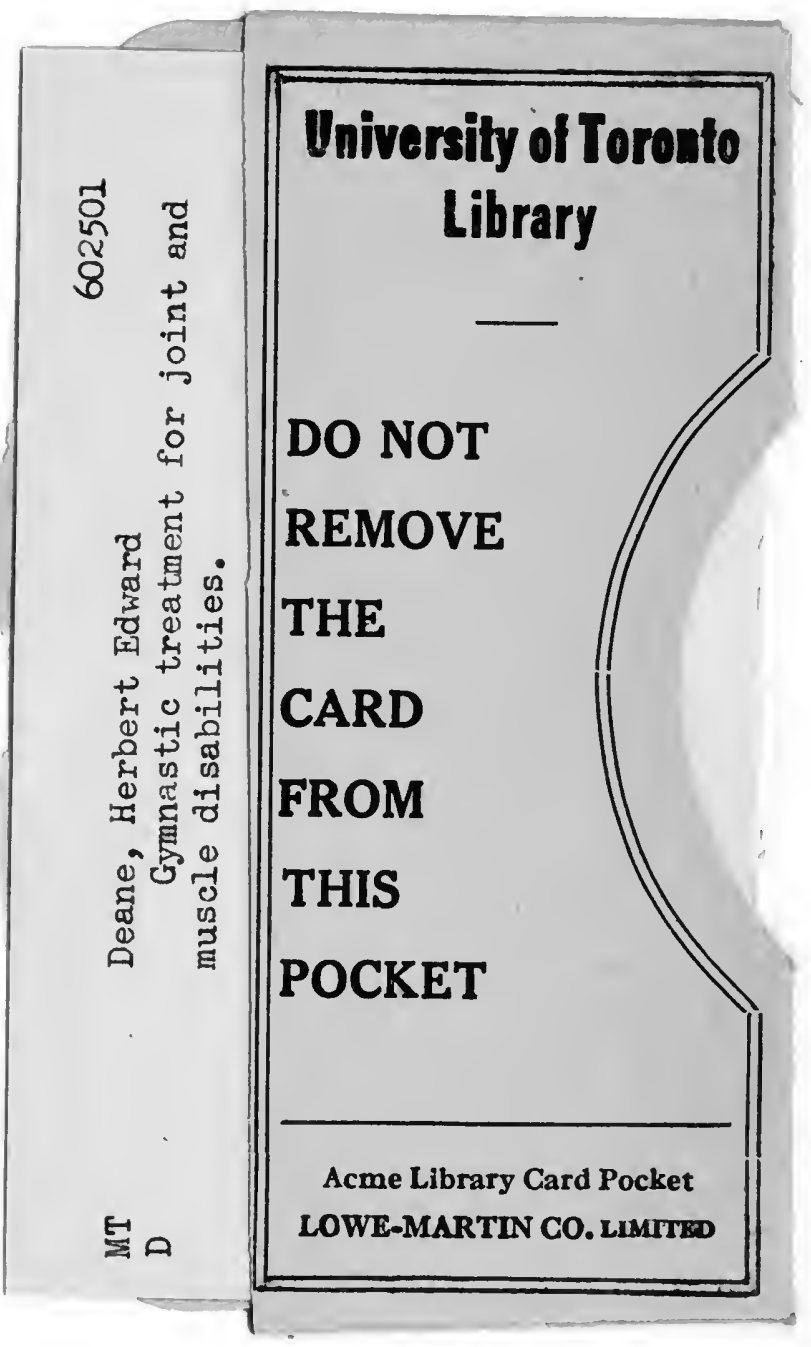




\section{Songe}

